\title{
Kinetic theory and mathematical model of cell metabolism
}

\author{
Motoyosi Sugita \\ Laboratory of Physics, Hitotsubasbi University, \\ Kunitachi, Tokyo, Japan
}

KURZFASSUNG: Kinetische Theorie und mathematisches Modell des Zellstoffwechsels. Obwohl der Stoffwechsel eine physikalisch und chemisch äußerst komplizierte Prozeßfolge ist, kann seine Kinetik durch ein hydrodynamisches Modell veranschaulicht werden, in welchem das Niveau der Flüssigkeit dem chemischen Porential entspricht. Die Funktionen sowohl des Intensitätsfaktors als auch des Drosselfaktors sind jedoch stark nicht-linear, so daß eine kontinuierliche Analyse, die auf Differentialgleichungen der Kinetik beruht, Schwierigkeiten bereiten. In die Differentialgleichungen der Kinetik, beispielsweise von mRNA oder Repressor, werden daher binäre Parameter eingeführt, da die entsprechenden molekularkinetischen Überlegungen sonst sehr komplizierte mathematische Modelle ergeben, die es erschweren, qualitative Angaben über das Regelungssystem zu machen; dafür gestattet aber die vorgeschlagene Methode nützliche Vereinfachungen. Zur Simulation wird ein System von Analogrechner und elektromechanischem Relaiskreislauf herangezogen. Liegt die Ausbeute der Rechenmaschine, etwa an Repressormenge, ïber oder unter einem bestimmten Schwellenwert, so wird ein Impuls durch den Schmitt-Kreislauf gegeben. Der Impuls wird dem Relaiskreislauf zugeführt, welcher als molekularer Automat angesehen werden kann und das kontinuierliche System wie eine Fabrik durch einen Computer reguliert. Durch entsprechende Vereinfachung des Kreislaufs und durch Vernachlässigung der Verzögerung, die durch Analogmaschine und Schmitt-Kreislauf entsteht, wird das schon früher mitgeteilte Modell erhalten.

\section{INT'RODUCTION}

Mathematical analysis or model formation of living things has increasingly gained in importance. Several biomathematical groups, including the Pennsylvania school of Chance, Garfinkel \& Hrggins in America and the group around Hess in Germany, are now doing pioneerwork in the use of computers. A mathematical theory of kinetics had been developed earlier by biologists, such as v. BERTALANFFY.

In 1961 the "International Conference on Biomathematics" was held at Cullowhee, North Carolina, U.S.A. Important participants were RAshevsky and other scientists of the pioneering Chicago school (proceedings were edited by Lucas and published in 1962). In 1963 a special edition of the Annals of New York Academy of Sciences (Volume 108) reported on the computer analysis in biomedical research. In 1965 a "Summer Coloquium" was arranged in Colorado with biomathematical analysis as the main topic, and the "6th International Conference on Medical Electronics and 
Biological Engineering" was held in Tokyo. At the latter meeting many sections were devoted to topics of mathematical analysis and computer simulation; BELlMaN (1965) gave a special lecture on "Mathematical Problems Arising in Biomedical Research".

Cybernetists have a unique way of thinking, which takes them far afield the ordinary continuous analysis based upon molecular biology. This is revealed by a look into the volumes of "Progress in Biocybernetics" (edited by WIENER \& SCHADÉ 1964, 1965). These schools, however, will be unified, I hope, in the not-too-distant future.

There are two principal approaches of mathematical analysis or model formation with living things: One is continuous analysis relying upon the differential equations of kinetics and using a differential analyzer, which may be an analogue computer (HENMETS 1964, 1966) or a digital computer programmed for this purpose (Hess \& BRAND 1966). The second approach is the fin ite mathe $m$ a t ics exemplified by the automaton theory (STAFL 1965a, b), in which a set of discrete states and their changes are taken into consideration.

These two approaches are quite different in their mathematical nature, and it may hardly be possible to cover the field of the former by using the latter and vice versa. Nevertheless, there are close relations and overlappings between both approaches. The author has tried to introduce a digital analysis and an application of a switching circuit model into a biochemical system (Sugrta 1961a, 1963; SugrTa \& Fukuda 1963). This concept was appreciated by GoonwIN (1963) as a preliminary approximation but also criticized, since such a way of thinking would be inadequate in a field where continuous analysis is desired, as is ordinarily the case in biochemical systems. STAHL (1965a, b) expressed the same opinion; he himself, however, is trying to apply his theory of automaton to a system that includes enzyme reactions, since he considers each system of enzyme reactions as a kind of automaton. It seems to me that if he tries to extend the finite mathematics to the field of a continuous one, then such a procedure is not adequate. However, there is a possibility that a certain enzyme system shows digital behaviour (GARFINKEL 1965), and he may consider such a system to be an automaton. In the field of continuous analysis a digital system, when it is adequately programmed, may, for instance, be applied as a differential analyzer and be considered to represent a kind of quasi-continuous system although it can also be used as a logically functioning system. In a general purpose digital computer the two functions therefore are only differentiated in the form of software.

In this report an attempt is undertaken to unify the two types of mathematical analysis by means of introducing binary numbers into the differential equations of kinetics and applying a hybrid computing system, namely of a switching circuit and an analogue computer, which is only a simple kind of differential analyzer of limited accuracy. It is easy to derive the switching circuit model proposed earlier (SugrTA 1963, Sugrta \& FuKUDA 1963) as the result of certain approximations and simplifications (SUGITA 1965a). In this case the analogue part of the hybrid system may be shown to correspond to delay units of the switching circuit, which constitutes the molecular automaton (SUGITA 1963).

Our approach may be considered a simplification of the orthodox method of continuous analysis, in which nonlinear differential equations are applied to represent the 
kinetics of a metabolic system. If we introduce the step-function approximation for representing non-linearity, we can get a differential equation of kinetics which possesses binary parameters.

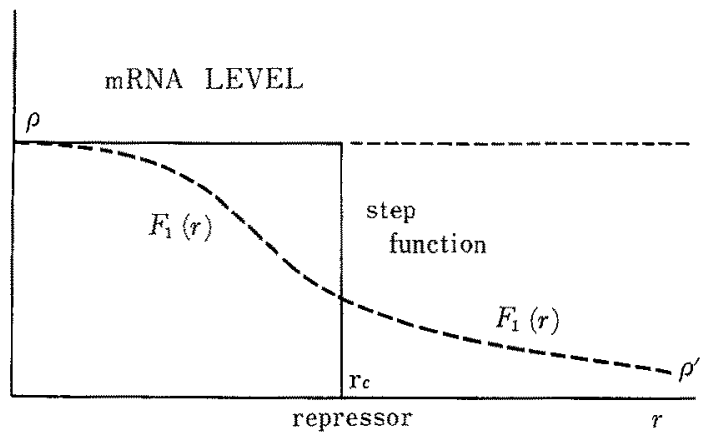

Fig. 1: Step-function approximation. In this graph $r$ was used instead of $y, r_{\mathrm{e}}$ instead of $y_{\mathrm{e}}$, $F_{1}(r)$ instead of $F_{1}(y), o$ instead of $a$ and $\varrho^{\prime}$ instead of $b$

We start, for example, with the following equation

where

$$
\frac{d y}{\mathrm{dt}}=F(y)-k y
$$

and

$$
\begin{aligned}
F(y) & =\overline{a f(y)}+b \mathrm{f}(y) & & \\
\mathrm{f}(y) & =1 & & \text { when } \mathrm{y} \geqq \mathrm{y}_{\mathrm{e}} \\
\mathrm{f}(y) & =0 & & \text { when } \mathrm{y}<\mathrm{y}_{\mathrm{e}}
\end{aligned}
$$

$a$ and $b$ are constants and $y_{\mathrm{c}}$ is a threshold value. $\overline{\mathrm{f}(y)}$ is the negation of the binary function $\mathrm{f}(y)$. Figure 1 shows that a non-linear function $\mathrm{F}(y)$ is represented by a stepfunction, which has the value $a$ when $y<y_{\mathrm{c}}$ and $b$ when $y \geqq y_{\mathrm{c}}$. (Somewhat altered symbols are used in Fig. 1.) Such a step-function approximation is frequently used in mathematical physics, for example, in the square well potential in the ScHRöDINGER equation. The idea of this approximation may be related to that of quasi-linearization of BellMAN, GLuss \& Roth (1964).

If we are assuming discrete states corresponding to the binary parameters like $\mathrm{f}(y)$, which are the object of finite mathematics, then this analysis could provide an approximate simplification of the continuous analysis. However, it is very difficult to deel with strongly non-linear differential equations. Even a digital computer of large capacity may in some cases be insufficient if the switching of parameters or a stepfunction approximation is not used. Therefore, the finite thathematics might correspond to one extreme of strong non-linearity and the continuous one to another extreme.

An additional limit to continuous analysis arises if a continuous change brings about a discontinuous change, which may be registered by certain means and may in turn control the system in a new mode corresponding to it. Spore formation of bacteria, fertilization and cell differentiation may deliver examples of such changes. Consequently, if we would rely upon continuous analysis only and use the computer beyond the limit mentioned, we could not obtain biologically significant results. It is neces- 
sary, therefore, to hybridize the two types of analysis. This method of unified analysis may also be useful in the case of digital computer, if we combine the two types of softwares.

A close relation exists between non-linearity of kinetic equations and feedback control of metabolic systems. Thus the idea of information or feedback in biochemical systems has first to be clarified. This will be done in the following section.

\section{HYDRAULIC MODEL OF KINETICS AND REGULATION OF CELL METABOLISM}

In the living organism substances of higher free energy are taken up and consumed. The rate processes of this free energy consumption are driven by intensive factors like the chemical potential along the corresponding reaction coordinate or metabolic pathway. How to define the chemical potential in a dynamical system, which is not in thermodynamic equilibrium will be discussed later in appendix $I$.

\section{Regulation of the direct type}

In a dynamical system there may be reaction coordinates, along which the field of chemical potential vanishes. Such coordinates may be called "quasi-equilibrium" coordinates (Sugrta 1957a, b), since the total system is not really in equilibrium. For

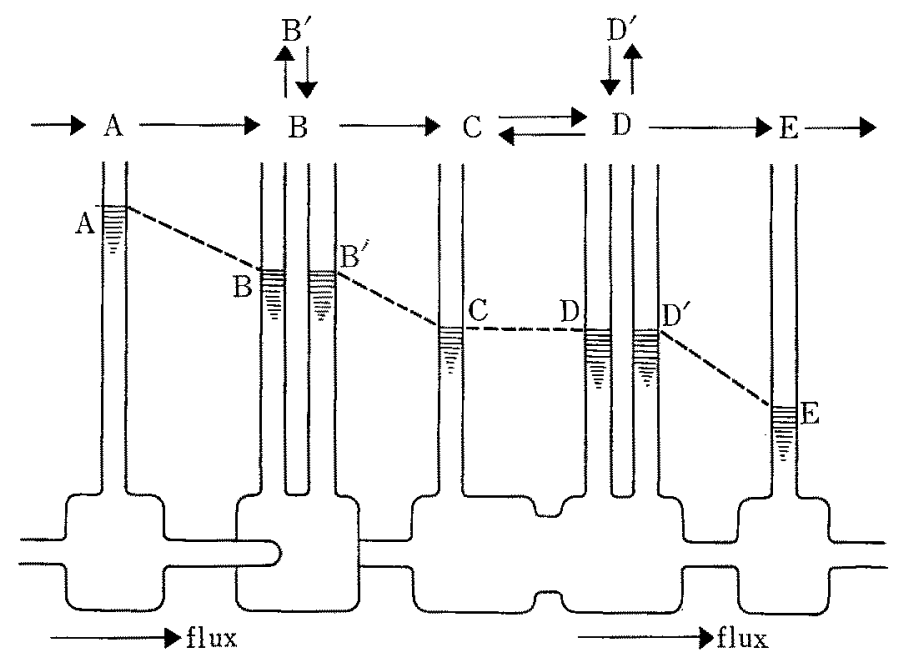

Fig. 2: Hydraulic model and quasi-equilibrium

instance, consider the reaction system of Figure 2, which can be represented by a direct analogue model, where the difference in water levels may correspond to the field of chemical potential and the flux of reactions belonging to the metabolic pathway may 
be represented by the rate of flow of the fluid through the pipe. Chemical reactions can not be expressed by a change in the ordinary space coordinate but, nevertheless, we may use the term "reaction coordinate" concerning the model of a pipe system (GLASSTONE, LAIDLER \& EYRING 1941). Such a quasi-equilibrium can be observed not only in biochemical reactions as such but also in processes of membrane permeability. If artificial disturbances are acting on this quasi-equilibrium (of $\mathrm{B}$ and $\mathrm{B}^{\prime}$ or $\mathrm{C}, \mathrm{D}$ and $\mathrm{D}^{\prime}$ in Figure 2) then the direct counteraction of recovering forces (according to the law of Le Chatelier-Braun) appears. In this kind of regulation the flux system is in a dynamical balance or equilibrium, while the total system is far away from a thermodynamical equilibrium.

It is interesting to note that the so-called metabolic map can be represented by such a pipe system, in which the fluid in a tank corresponds to a chemical substance within a compartment. The level difference between the two tanks corresponds qualitatively to the intensive factor of this metabolic pathway but not quantitatively. Let us consider a chemical reaction of the following type

$$
\lambda_{1} \mathrm{~A}_{1}+\lambda_{2} \mathrm{~A}_{2}+\ldots \rightarrow \nu_{1} \mathrm{~B}_{1}+\nu_{2} \mathrm{~B}_{2}+\ldots
$$

Then the flux of this rate $(J)$ process can be given by

$$
\text { where } \quad \begin{aligned}
J & =\sigma\left(\mathrm{e}^{\mu / R T}-\mathrm{e}^{\mu} / R T\right. \\
\mu & =\lambda_{1} \mu\left(\mathrm{A}_{1}\right)+\lambda_{2 \mu} \mu\left(\mathrm{A}_{2}\right)+\ldots \ldots \\
\mu^{\prime} & =\nu_{1} \mu\left(\mathrm{B}_{1}\right)+\nu_{2} \mu\left(\mathrm{B}_{2}\right)+\ldots
\end{aligned}
$$

and $\mu\left(A_{i}\right)$, for example, is the chemical potential per mol of $A_{i}$ in the reaction system 1 .

The term "compartment" may be defined as a region wherein both the functional form and the value of the chemical potential are the same.

In equation (2.2) $\mathrm{e}^{u / R T}-\mathrm{e}^{\mu / R T}$ represents the intensive factor or the socalled field of chemical potential along this reaction coordinate, and $\sigma$ is the proportional constant which may be called throttling factor. In chemical equilibrium we have $J=0$ and

$$
\mu=\mu^{\prime} \text { or } \Delta \mu=\mu-\mu^{\prime}=0
$$

In general, however, the field of chemical potential is not the difference $\Delta \mu=\mu-\mu^{\prime}$. Therefore a quantitative correspondence between the level of the fluid and of the chemical potential cannot occur. However, it seems justified to consider a direct analogue model of a pipe system instead of a mathematical model of kinetic equations

1. If $G$ is the Grbss' potential, then we have

$$
\begin{gathered}
\frac{d G}{d t}=\sum_{\mathrm{j}} \frac{\partial G}{\partial n\left(\mathrm{~A}_{\mathrm{i}}\right)} \frac{d n\left(\mathrm{~A}_{\mathrm{i}}\right)}{d t}+\sum_{\mathrm{i}} \frac{\partial G}{\partial n\left(\mathrm{~B}_{\mathrm{j}}\right)} \frac{d n\left(\mathrm{~B}_{\mathrm{j}}\right)}{d t}=-\left(\mu-\mu^{\prime}\right) \frac{d \xi}{d t} \\
\frac{d n\left(\mathrm{~A}_{\mathrm{i}}\right)}{d t}=-\hat{\lambda}_{\mathrm{i}} \frac{d \xi}{d t}, \quad \frac{d n\left(\mathrm{~B}_{\mathrm{j}}\right)}{d t}=\nu_{\mathrm{j}} \frac{d \xi}{d t}
\end{gathered}
$$

where

and $\frac{d \xi}{d t}$ is the parameter introduced by DE DONDER concerning the flux of (2.1) from left to right. This quantity, $\left(\mu-\mu^{\prime}\right) \frac{d \xi}{d t} \quad$ may be the product of $\mathrm{T}$ and the entropy production of this rate process. ( $\frac{d \xi}{d t}$ may be equal to $J$, see (10) of appendix II.) 
because the former appears to be more intuitive than the latter, if we do not insist upon quantitative exactitude.

An exponential form of the intensive factor like equation (2.2) can also be brought about by a semi-conductor where OHM's law represents the limiting case of expansion of the exponential function and neglects any higher order term.

From equation (2.4) we can derive the well-known relation of mass action. Let us put

$$
\begin{aligned}
& \mu=\sum_{\mathrm{i}} R T \log c_{\mathrm{i}}^{2 \mathrm{i}}+\mu_{0} \\
& \mu^{\prime}=\sum_{\mathrm{j}} R T \log c_{\mathrm{j}^{\prime}} \dot{\mathrm{j}}+\mu_{0}^{\prime}
\end{aligned}
$$

where $c_{i}$ and $c_{j}$ are the concentrations of $A_{i}$ and $B_{j}$ respectively. Then, in chemical equilibrium, we have

$$
\Delta \mu=R T \log \frac{\Pi_{\mathrm{i}} c_{\mathrm{i}}^{\lambda \mathrm{i}}}{\Pi_{\mathrm{j}} c_{\mathrm{i}}{ }^{2 j}}+\Delta \mu_{0}=0
$$

where

$$
\Delta \mu_{0}=\mu_{0}-\mu_{0}^{\prime}
$$

is the standard free energy. It can be written:

$$
-\Delta \mu_{0}=R T \log K
$$

where $K$ is the equilibrium constant. The law of mass action can be interpreted as the balance of forward and backward reactions, the rates of which can respectively be represented by

$$
J_{1}=k \Pi_{\mathrm{i}} c_{\mathrm{i}}^{\lambda \mathrm{i}} \quad J_{2}=k^{\prime} \Pi_{\mathrm{j}} c_{\mathrm{j}}{ }^{j \mathrm{j}}
$$

where $k$ and $k^{\prime}$ are rate constants. Then

$$
J=J_{1}-J_{2}
$$

and in chemical equilibrium $J_{1}=J_{2}$; thus equation (2.6) is obtained, if we put

$$
k^{\prime} / k=K
$$

In dynamic systems $J_{1} \neq J_{2}$ and (2.10) coincides with (2.2), if we put

$$
k=\sigma \mathrm{e}^{\mu \mathrm{o} / R T^{\prime}} \text { and } k^{\prime}=\sigma \mathrm{e}^{\mu^{\prime} \mathrm{o} / R T}
$$

and take (2.5) into consideration. Therefore, equations (2.9) and (2.10) stand for the generalization of the law of mass action, which leads to the inference that we ought not consider this law in too narrow a sense as if it were a law of chemical equilibrium alone. In Figure 2 the throttling factor, $\sigma$ between $B$ and $B^{\prime}$ or $C, D$ and $D^{\prime}$ is large. If we rewrite the equation (2.2) in the following form

$$
\mathrm{e}^{\mu / R T}-\mathrm{e}^{u^{\prime} / R T}=\frac{J}{\sigma}
$$

and assume that $\sigma$ is very large, we can put

$$
\mathrm{e}^{\mu / R T} \doteq \mathrm{e}^{\mu^{i} / R T}
$$

although $J \neq 0$. This introduces the idea of quasi-equilibrium. In membrane equilibrium we have

$$
\Delta \mu+F \Delta \varphi=0
$$


where $\Delta \mu$ is the difference of chemical potential of an ion, $F$ is the Faraday constant and $\Delta \varphi$ is the difference of electrostatic potential. If this equilibrium is disturbed and ionic flux $I$ occurs, then instead of (2.14) we arrive at

$$
\Delta \mu^{\prime}+F \Delta \varphi^{\prime}=I / \sigma
$$

which corresponds to (2.13). If we can put $\Delta \mu=\Delta \mu^{\prime}$, then we have from (2.14) and $\left(2.13^{\prime}\right)$

$$
\Delta \varphi^{\prime}-\Delta \varphi=I /_{\sigma} F
$$

and we can put $\Delta \varphi^{\prime} \fallingdotseq \Delta \varphi$, if $I / \sigma F$ is very small (OHKI 1965).

\section{REGULATION OF THE INDIRECT OR PARAMETRIC 'TYPE}

There is still another type of regulation which is not a direct but an indirect one. For instance, let us consider an end product inhibition of the type described in Figure 3, where the function of the enzymes $E_{2}, E_{3}$ etc. is not variable and only that of $E_{1}$ is

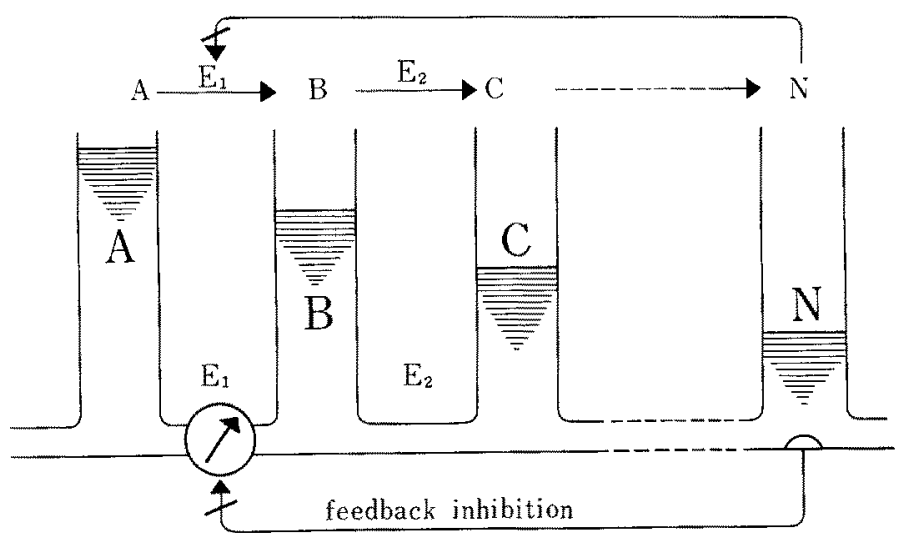

Fig. 3: Feedback inhibition

changeable and undergoes inhibition by the end product $N\left(E_{1}\right.$ may be an allosteric protein). Although the field of chemical potential driving $A \rightarrow B$ is kept constant, the flux of the reaction can be influenced through variation of the function of $E_{1}$. In Figure $3 \mathrm{E}_{1}$ is represented by a valve which is controlled by the signal emitted by $N$.

Thus here no direct coupling between $N$ and $A \rightarrow B$ exists. In some biochemical cycle, on the other hand, a reaction product may have some material correlation with the reaction $\mathrm{A} \rightarrow \mathrm{B}$. In conjugate reactions (e. $\mathrm{g}$. of $\mathrm{S} \rightarrow \mathrm{P}$ and ATP $\rightarrow$ ADP or $\mathrm{ADP} \rightarrow \mathrm{ATP})$ a coupling of energy between the two types is required. In the case considered by us, however, $A \rightarrow B$ is energetically (and materially) independent of $N$, although, nevertheless, $N$ influences the magnitude of the flux of $A \rightarrow B$. Such an effect is called an indirect or parametric one: the rate of the reaction $A \rightarrow B$ is controlled by $\mathrm{N}$ parametrically. In the study of life processes indirect regulations of 
this type may assume much more importance than the direct ones. Consequently, the present report considers primarily parametric regulations.

Even parametric action may be represented by two types: an a n a log u e or continuous interaction as it occurs in feedback interactions, and a digital onoff-nature type, exemplified by the performing or lacking action of an operator gene. In the regulation of the tryptophan level, both types of interaction may coexist (Sugrta 1966a, b). Of these two types of parametric actions, the digital or on-off interaction is mainly taken into consideration here. It will be shown that such a digital conceptualization becomes a kind of mathematical approximation or simplification of choice whenever a regulation system of strong, non-linear nature has to be investigated.

The idea of the equifinality of v. BertalAnFFy has some relation to direct (Fig. 2) as well as indirect regulation (Fig. 3), although equifinality might also be realized by several other mechanisms, more complex in nature and in some cases with a set value (as in automatic control). A recover process may correct any deviation from the normal course and regulate the system. In this regard the nature of parametric action can be clarified (Sugita 1965b). In Figure 4 a direct action occurs between

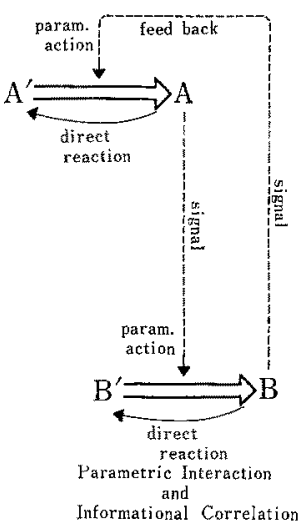

Fig. 4: Parametric action and transmission of information

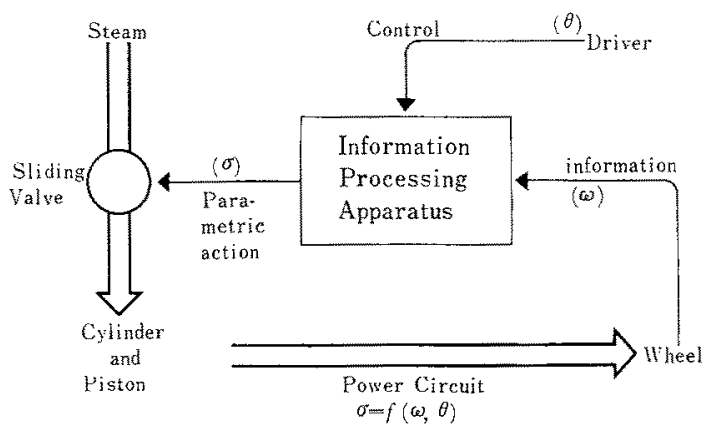

Fig. 5: Direct and indirect action

$B^{\prime}$ and $B$ but not between $A$ and $B$. A sends only a signal to the reaction $B^{\prime}-B$ which controls this direct action of $B^{\prime}-B$. The direct action of $B-B^{\prime}$ is maintained in a latent form and the "possibility" of this action is "realized" parametrically by the triggering signal of A. If $B$ sends a signal back to the system of $A^{\prime}-A$ and controls their interaction parametrically, a type of indirect action appears called feedback. The transmission of parametric action may generally be termed "information".

Figure 5 demonstrates an example of the coupling of direct and indirect or parametric interaction. Such a coupling - based on a comparison with a locomotive - may be obvious in many biological systems. In this paper a system with parametric interaction and complex functions due to such a correlation, including feedback, is called "cybernetic system". Such systems may reveal interesting functions or character- 
istics. The higher the degree of indirect interaction, the higher is the function of the system or the system's behaviour. From the point of view of a pure scientist, cybernetics may be considered a tool for studying such a function or for designing and manufacturing such systems (SugrTA 1965b).

The parametric action is ineffective if the intensive factor is not strong enough. ELSASSER (1958) has pointed out the important fact that in a chemical equilibrium the function of an enzyme cannot be prominent. If the deviation from the thermodynamic equilibrium is small, the intensive factor of every reaction coordinate is also small, and the flux may simply be an expanded linear function of the intensive factors. Indeed, in the ordinary phenomenological theory of irreversible processes, only linear terms are taken into account, and throttling factors are considered as being constant. In such a system the parametric action or feedback cannot operate.

In dynamic systems based on parametric interaction, however, the flexibility of the throttling factor plays an important role, and I have proposed a theory considering the throttling factor, like the functions of other variables, under the heading of "theory of flexible throttle" (Sugrta 1958, 1961a). In the future this theory is likely to become another kind of thermodynamics of irreversible processes, dealing with strong deviations from equilibrium, and in this respect will differ from the ordinary theory of irreversible thermodynamics, yet will supplement it.

The physico-chemical nature of the parametric action will be discussed later. If a potentiality or latent possibility is lacking, the flexibility of the throttling factor cannot release any response (SUGITA 1965b). This fact has frequently been neglected in the theoretical considerations of the "information theory", which leads us to the conclusion that - although very useful as an abstract theory - the information theory has to be applied carefully; we have to bear in mind that it has a rather narrow scope.

Physically, information represents a pattern which releases a certain response; its nature is non-stochastic. In information theory, however, we replace the source of information artificially and mathematically by a stochastic process which emits a pattern according to the frequency of its appearance. We must not confuse the idea of information as a physical pattern having parametric action and the abstract mathematical idea playing the leading role in information theory. The problem in the latter is to find an abstract time series, similar to the MARKov chains and offering an approach especially relevant to information technology.

\section{DIFFERENTIAL EQUATIONS OF KINETICS HAVING BINARY PARAMETERS}

\section{Kinetics of messenger RNA formation}

Genetic information of the structural gene (SG) exerts the parametric action on messenger RNA (mRNA) formation, i. e. controls this formation parametrically. Considering for instance $\beta$-galactosidase formation of $E$. coli, Sugrta (1965a) has introduced a binary number $\mathrm{g}\left(\mathrm{z}^{+}\right)$, which is $\mathrm{g}\left(\mathrm{z}^{+}\right)=1$

when the organism is a wild type and $g\left(z^{+}\right)=0$, when it is not $z^{+}$ 
The rate of formation of the corresponding mRNA may be a function of some controlling molecule or regulatory metabolite; if this acts as inhibitor it is called repressor. We will denote this function as $F_{1}(r)$. If the quantity of repressor $r$ is sufficiently large, $F_{l}(r)$ may be very small, say $\varrho^{\prime}$. If, on the other hand, $r$ is very small, then $F_{1}(r)$ may reach a saturation value $\varrho$. From experiments we know that $\varrho^{\prime} \sim 10^{-4} \varrho$. $F_{1}(r)$ may be evaluated by molecular kinetic considerations (e. g. HeINMETs 1964, 1966). However, let us use a step-function approximation of the following kind:

$$
F_{1}(r)=\varrho \overline{\mathrm{f}(r)}+\varrho^{\prime} \mathrm{f}(r)
$$

where

$$
\begin{array}{ll}
\mathrm{f}(r)=1 & \text { when } r \geqq r_{\mathrm{c}} \\
\mathrm{f}(r)=0 & \text { when } r<r_{\mathrm{c}}
\end{array}
$$

and $r_{\mathrm{e}}$ is a threshold value of $r$. Then the rate of mRNA formation is

$$
\mathrm{g}\left(\mathrm{z}^{+}\right) F_{1}(r)=\mathrm{g}\left(\mathrm{z}^{+}\right)\left\{\varrho \overline{\mathrm{f}(r)}+\varrho^{\prime} \mathrm{f}(r)\right\}
$$

The rate of mRNA formation depends on the state of the operator gene (OG) too. There are mutants like $o^{c}$ or $o^{\circ}$ other than $o^{+}$(wild type). In the case of $o^{c}$ a function $F_{2}(r)$ is introduced instead of $F_{1}(r)$, which may approximately be expressed by

$$
F_{2}(r)=\varrho^{\prime \prime} \overline{f(r)}+\varrho^{\prime \prime \prime} \mathrm{f}(r)
$$

where $\varrho^{\prime \prime}$ and $\varrho^{\prime \prime \prime}$ are constants and

$$
\varrho^{\prime \prime}=4 \varrho^{\prime \prime \prime}
$$

Then the general form of the rate of mRNA formation is

$$
\mathrm{g}\left(\mathrm{z}^{+}\right)\left\{\mathrm{g}\left(\mathrm{o}^{+}\right) F_{1}(r)+\mathrm{g}\left(\mathrm{o}^{\mathrm{c}}\right) F_{2}(r)\right\}
$$

which is equal to zero in the case of $o^{o}$, if we assume that $\overline{g\left(o^{\circ}\right)}=g\left(o^{+}\right)+g\left(o^{c}\right), \overline{g\left(o^{+}\right)}$ $=\mathrm{g}\left(\mathrm{o}^{\circ}\right)+\mathrm{g}\left(\mathrm{o}^{\mathrm{c}}\right)$, that is, no overlapping between $\mathrm{o}^{+}, \mathrm{o}^{\mathrm{c}}$ and $\mathrm{o}^{\circ}$ occurs. Let us assume for simplicity

$$
\varrho^{\prime} \fallingdotseq 0, \quad \varrho \fallingdotseq \varrho^{\prime \prime} \doteqdot \varrho^{\prime \prime \prime}
$$

then we have, instead of (3.6)

$$
\varrho \mathrm{g}\left(\mathrm{z}^{+}\right)\left\{\mathrm{g}\left(\mathrm{o}^{+}\right) \overline{\mathrm{f}(r)}+\mathrm{g}\left(\mathrm{o}^{c}\right)\right\}=\varrho \mathrm{g}\left(\mathrm{z}^{+}\right) \omega
$$

where

$$
\omega=\mathrm{g}\left(\mathrm{o}^{+}\right) \overline{\mathrm{f}(r)}+\mathrm{g}\left(\mathrm{o}^{\mathrm{c}}\right)
$$

is a binary variable describing the state of the OG; $\omega=1$ corresponds to its open state and $\omega=0$ to the closed state. Equation (3.8) is equal to the relation derived formerly (SUGITA \& FUKUDA 1963), where somewhat different notations were used; qualitatively and approximately it may be a useful variable but quantitatively it is not.

The attempt to obtain a quantitative result relying upon such a variable (SUGITA \& FUKUDA 1963), in which the kinetic equation is written in

$$
\frac{d m}{d t}=\varrho \omega \mathrm{g}\left(\mathrm{z}^{+}\right)-k_{m} m
$$

cannot be adequate because here the binary variable is not used adequately. In 
considering the computer control of $\beta$-galactosidase formation, $i$. e. the control under molecular automaton composed of DNA, RNA, repressor or inducer and enzymes, we have to use the binary variable $f(r)$ instead of $\omega$ and should write instead of (3.9)

$$
\frac{d m}{d t}=\mathrm{g}\left(\mathrm{z}^{+}\right)\left\{\mathrm{g}\left(\mathrm{o}^{+}\right) F_{1}(r)+\mathrm{g}\left(\mathrm{o}^{c}\right) F_{2}(r)\right\}-k_{m} m
$$

where $m$ is the quantity of mRNA and $k_{m}$ is its decay constant.

Goonwin (1963) argues against the assumption of an on-off nature of the operator gene by referring to the leaky production of $\beta$-galactosidase. If, however, the binary variable $f(r)$ is used instead of $\omega$, our consideration may no longer be criticized, since the small value assumed for $\varrho$ ' would directly correspond to the leaky production.

\section{Kinetics of repressor formation}

The kinetic equation of repressor formation is in the case of $\mathrm{i}^{+}$written as

$$
\frac{d r}{d t}=A-k r
$$

where

$$
A=\frac{k r_{\mathrm{c}}}{1+a\left(J-J_{0}\right)^{\mathrm{n}}}
$$

$r_{c}$ and $J_{0}$ are respectively the critical values of $r$ and $J$. We assume that $a>0, a J^{n_{0}}<1$ and $n$ is an odd number. $k$ is the decay constant of $r$, and a simple form $k r$ is assumed here. Therefore, the steady state value of $r$ is

$$
(r)_{\text {steady }}=\frac{A}{k}=\frac{r_{\mathrm{c}}}{1+a\left(J-J_{0}\right)^{\mathrm{n}}}
$$

and

$$
\left.\begin{array}{ll}
(r)_{\text {steady }} \geqq r_{\mathrm{c}} & \text { when } J \leqq J_{0} \\
(r)_{\text {steady }}<r_{\mathrm{c}} & \text { when } J>J_{0}
\end{array}\right\}
$$

(3.11) is only an assumption and any other form can be adopted if the condition of (3.12) is satisfied.

In the case of $i^{s}$ let us assume

$$
\begin{aligned}
& \frac{d r}{d t}=B-k r \\
& B=\frac{k r_{c}}{1+b\left(J-J_{0}^{t}\right)^{n}}
\end{aligned}
$$

where $b>0$ and $b J_{0}{ }^{\mathrm{n}}<1 . J_{0}^{\prime}$ is assumed to be larger than $J_{0}$ of (3.11). According to the experimental facts

$$
J_{0}^{\prime} \fallingdotseq(100 \sim 1000) J_{0}
$$

In ordinary experimental condition

$$
(r)_{\text {steady }}=r^{\prime}=\frac{r_{c}}{1-b J^{\prime}{ }_{0}^{n}}>r_{c}
$$

If for simplicity we take only $i^{+}, i^{s}$ and $i-$ into account, then we have instead of (3.10) or $\left(3.10^{\prime}\right)$, 


$$
\frac{d r}{d t}=A \mathrm{~g}\left(\mathrm{i}^{+}\right)+B g\left(\mathrm{i}^{\mathrm{s}}\right)-k r
$$

As there is no overlapping between $\mathrm{i}^{+}, \mathrm{i}^{s}$ and $\mathrm{i}^{-}$, we have

$$
\overline{g\left(i^{+}\right)}=g\left(i^{s}\right)+g\left(i^{-}\right), \overline{g\left(i^{-}\right)}=g\left(i^{+}\right)+g\left(i^{s}\right) .
$$

So that, in the case of $i^{-}, g\left(i^{+}\right)=0, g\left(i^{s}\right)=0$ and $(r)_{\text {steady }}=0$. In general, we have from $\left(3.10^{\prime \prime}\right)$

$$
(r)_{\text {steady }}=\frac{r_{\mathrm{eg}}\left(\mathrm{i}^{+}\right)}{1+a\left(J-J_{0}\right)^{\mathrm{a}}}+r^{\prime} \mathrm{g}\left(\mathrm{i}^{\mathrm{s}}\right)
$$

If we define a two valued function $f(J)$, which is

and

$$
\mathrm{f}(J)=1 \quad \text { when } J \geqq J_{0}
$$

then we have $\quad f(r)=g\left(i^{+}\right) \overline{f(J)}+g\left(i^{s}\right)$

Equation (3.15) coincides with the relation derived in a preceding paper (SUGITA $8 x$ FUKUDA 1963), if we use the notation $r, i^{+}, i^{s}$ and $J$ instead of $f(r), g\left(i^{+}\right), g\left(i^{s}\right)$ and $\mathrm{f}(J)$. In the experiment of PARDEE, JACOB \& MoNOD (1959) the organism is at first $\mathrm{i}^{-}$ and after conjugation $\mathrm{i}^{+}$. So that we put in $\left(3.10^{\prime \prime}\right) \mathrm{g}\left(\mathrm{i}^{\mathrm{s}}\right)=0$ and $\mathrm{g}\left(\mathrm{i}^{+}\right)=0$ at first and $g\left(i^{+}\right)=1$ afterwards. Then this experimental result can be described mathematically.

Equation $\left(3.10^{\prime \prime}\right)$ may be generalized in the form:

$$
\frac{d r}{d t}=A \mathrm{~g}\left(\mathrm{i}^{+}\right)+B g\left(\mathrm{i}^{\mathrm{s}}\right)+C g\left(\mathrm{i}^{-}\right)+D g\left(\mathrm{i}^{\mathrm{t}}\right)+E \mathrm{~g}\left(\mathrm{i}^{\mathrm{t}} \mathrm{II}\right)+F g\left(\mathrm{i}^{\mathrm{r}}\right)-k r,
$$

where $C=0$ and $F$ may be an increasing function of $J$, i. e. $J$ is in this case co-repressor. In $\mathrm{i}^{\mathrm{t} I}$ and $\mathrm{i}^{\mathrm{t}} \mathrm{I} C$ and $D$ represent the function of temperature. In $\mathrm{i}^{\mathrm{t}} k$ may also be an increasing function of temperature. Therefore, $r$ decays at high temperature and according to HoRuch (1961) this organism behaves as if it were $\mathrm{i}-$. The temperature sensitive nature of the genetic control is observed only in the case of microorganisms. In higher organisms experimental evidence may be difficult to obtain; nevertheless, the fact concerning the strain $i^{t}$ of $E$. coli may hold for temperature adaptation of animals too.

\section{COMPUTER SIMULATION}

In Figure $6\left(A_{1}\right),\left(A_{2}\right)$ and $\left(A_{3}\right)$ correspond respectively to the kinetic equations of the inducer $J$, repressor $r$ and $m$ RNA $m$. In the case of $\left(A_{2}\right)$ a non-linear function generator is used corresponding to $A$ of (3.11) or $B$ of (3.11'), it and other mutants are neglected for simplicity. Relay circuit is used for representing the function of $\mathrm{g}\left(\mathrm{i}^{+}\right)$and $\mathrm{g}\left(\mathrm{i}^{\mathrm{s}}\right)$. In Figure 7 some kind of simplification is given, for instance a pulse corresponding to the binary function $f(J)=1$, which is generated by the Scrmrt trigger (S). Thus

$$
k r_{0}\left\{\mathrm{~g}\left(\mathrm{i}^{+}\right) \overline{\mathrm{f}(r)}+\mathrm{g}\left(\mathrm{i}^{\mathrm{s}}\right)\right\}
$$

is generated, and it is applied to $\left(A_{2}\right)$. In Figure 7 another simplification of equation (3.7) is adopted and the binary variable $\omega$ of (3.8) is used. Here the combination of 
$\left(A_{1}\right)--(S)$ and $\left(A_{2}\right)-(S)$ corresponds to the delay unit. Neglecting these delay units we obtain Figure 8, which may be rearranged into Figure 9 proposed by Sugita \& FuKudA (1963). Therefore, the switching circuit model, or the so-called "threshold
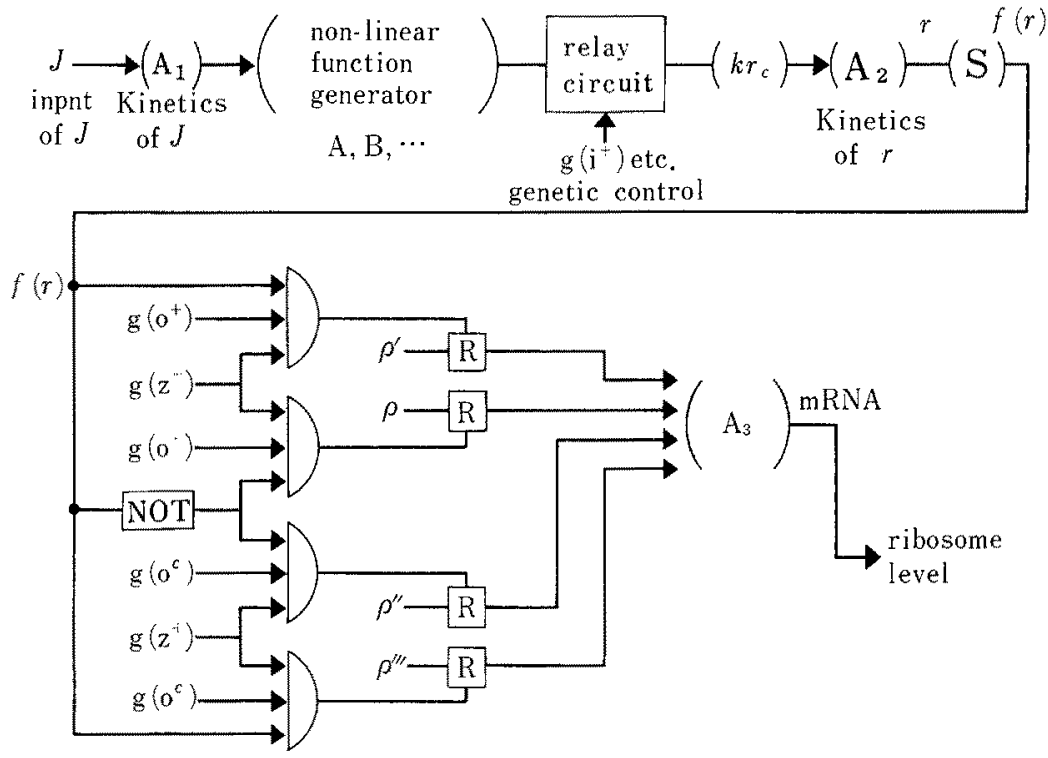

Fig. 6: Hybrid system simulating genetic control

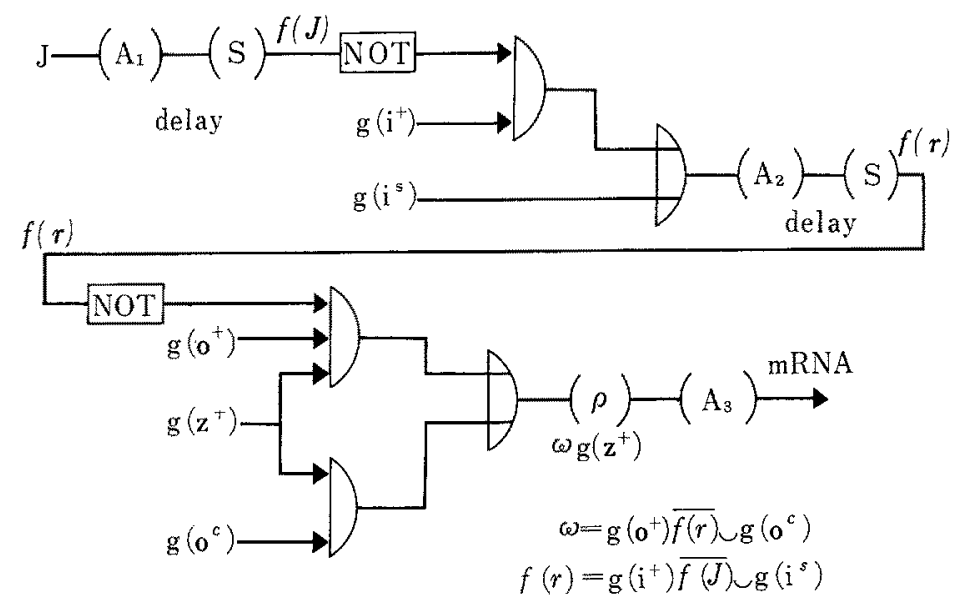

Fig. 7: Simplified model of the hybrid system: A2: Analogue circuit of kinetics of $r$; $S$ : Schmiтt circuit; $A_{3}$ : Analogue circuit of kinetics of $m$

logic", is only a crude approximation or simplification; but even by way of such simplification, we may observe important characteristics of such complicated reaction systems as are the living organisms. A reaction system or so-called primitive control system 
which makes a switching circuit appropriately and has delay units may be called molecular automaton (SugITA 1963). The biochemical systems in general, however, do not always represent such a digital system as was stressed by GoodwIN (1963). However, some kind of reaction system, including reactions at the genetic level, may constitute a digital system; the analogue part at the enzyme level plays the role of a delay unit. Therefore, we can adopt such a simplification. In this respect a continuous system may

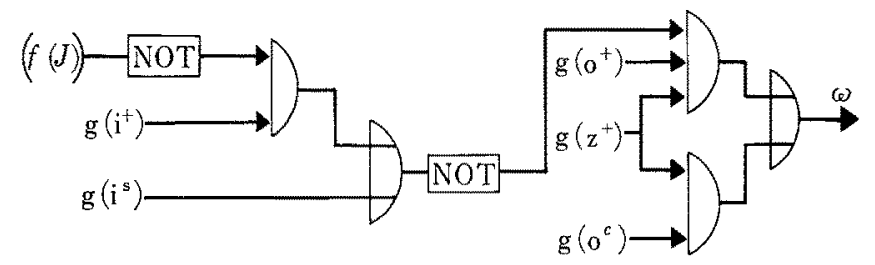

Fig. 8: Switching circuit model of genetic control

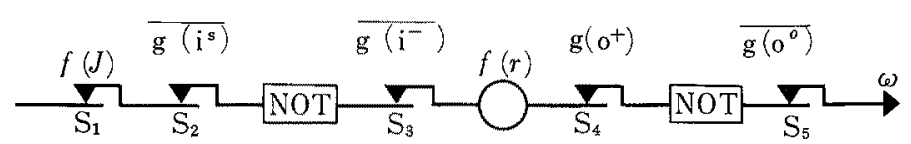

Fig, 9: Switching circuit model (rearranged)

be indispensable to an automaton, and the continuous analysis may be complementary to the finite one, even though a general purpose digital computer is used. Further, many in vivo reactions, whether they be analogue or continuous in nature, may stand under digital control; examples are: enzyme induction, cell division or differentiation, and spore formation of bacteria. Since such a digital consideration is only a mathematical simplification, the problem remains whether or not we are justified to start from a digital point of view.

\section{MATHEMATICAL MODEL OF CELL SIZE REGULATION}

We must be careful in extending a concept based on studies of microorganisms to higher organisms. While simple analogy or crude generalization is dangerous, abstract considerations and mathematical formulations may be of some help. YČAs, Sugita \& Bensam (1965) have discussed the mechanism of cell size regulation using mathematical models and an analogue simulation (Fig. 10). They have not yet acquired, however, the necessary experimental knowledge concerning $R_{1}$ and $R_{2}$, which are some kinds of regulatory metabolites; these may represent RNA or similar compounds; their molecular nature is left to future investigations. The mathematical model of YČAS, SUGITA \& BENSAM (1965) is the following:

$$
\begin{aligned}
& \frac{d R_{1}}{d t^{\prime}}=\overline{\mathrm{T}_{\mathrm{M}}} a_{1}-b_{1} R_{1} \\
& \frac{d R_{2}}{d t^{\prime}}=\overline{\mathrm{T}_{\mathrm{M}}} \mathrm{T}_{\mathrm{C}} a_{2}-b_{2} R_{2}
\end{aligned}
$$


where $T_{M}$ is the signal of mitosis (i. e. $T_{M}=1$ during mitosis and $T_{\mathrm{XI}}=0$ in the other case). $\overline{T_{M}}$ is the negation of $\mathrm{T}_{M}\left(\overline{\mathrm{T}_{M}}=1\right.$ shows that the cell is not in mitosis). $\mathrm{T}_{e}$ is another binary parameter, which is

$$
\begin{array}{ll}
\mathrm{T}_{\mathrm{c}}=1 & \text { when } \frac{R_{1}}{P} \geqq c \\
\mathrm{~T}_{\mathrm{c}}=0 & \text { when } \frac{R_{1}}{P}<c
\end{array}
$$

where $P$ is the total quantity of protein, $R_{1} / P$ is the concentration of $R_{1}$ in the cell and $c$ is the critical concentration; $a_{1}, a_{2}, b_{1}$ and $b_{2}$ are constants.

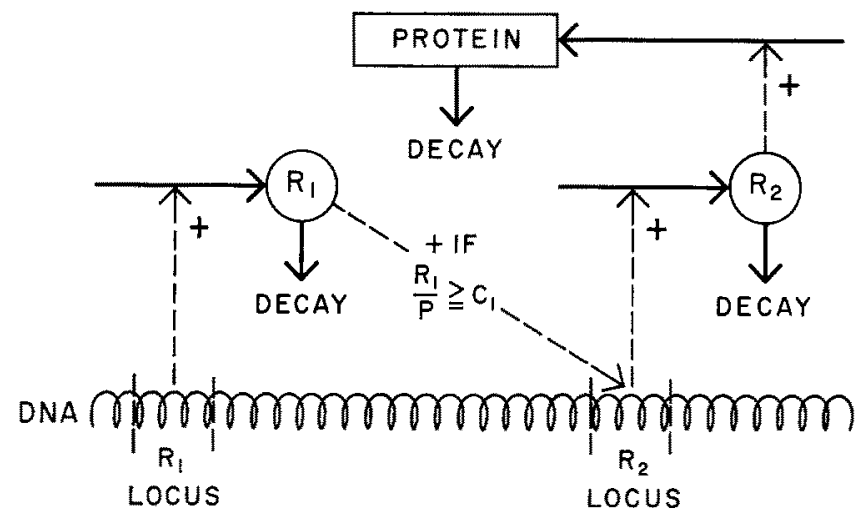

Fig. 10: Proposed model of cell size regulation. Solid lines indicate flux of material, broken lines catalytic action. The $R_{1}$ locus is assumed to be spontaneously active when mitosis terminates, the $R_{2}$ locus to be active only under the positive catalytic influence of $R_{1} . c$ is some present value

The kinetic equation of $P$ is assumed simply in the form:

$$
\frac{d P}{d t^{\prime}}=\alpha^{i} R_{2}-\beta^{\prime} P
$$

where $\alpha^{\prime}$ and $\beta^{\prime}$ are constants. If we assume that the rate of protein synthesis of a kind $\mathrm{i}$ is proportional to (mRNA) i, i. e.

$$
\begin{aligned}
& P_{\mathrm{i}}=(\text { proportional coefficient })_{\mathrm{i}}(\mathrm{mRNA})_{\mathrm{i}}=\text { rate of formation of } \mathrm{P}_{\mathrm{i}} \\
& \left.P=\sum_{\mathrm{i}} P_{\mathrm{i}}=\sum_{\mathrm{i}} \text { (prop. coeff. }\right)_{\mathrm{i}}(\mathrm{mRNA})_{\mathrm{i}}=\alpha^{\prime} R_{2}= \\
& \text { rate of formation of } \mathrm{P}
\end{aligned}
$$

where

$$
R_{2}=\sum_{\mathrm{i}}(\mathrm{mRNA})_{\mathrm{i}}
$$

then $R_{2}$ may be the total quantity of mRNA. These constants $a_{1}, a_{2}, b_{1}, b_{2}, \alpha^{\prime}$ and $\beta^{\prime}$, are difficult to know, so let us use the following reduced quantities,

$$
\begin{aligned}
& r_{1}=R_{1} /\left(\frac{a_{1}}{b_{1}}\right), \quad r_{2}=R_{2} /\left(\frac{a_{2}}{b_{2}}\right), p=\frac{P}{P_{1}} \\
& p_{1}=\frac{a_{1}}{b_{2} c}, \quad \alpha=\alpha^{\prime} \frac{a_{2}}{b_{2} a_{1}} c, \quad \beta=\beta^{\prime} / b_{2}
\end{aligned}
$$


Then we have instead of $\left(5.1^{\prime}\right),\left(5.2^{\prime}\right)$ and $\left(5.3^{\prime}\right)$

$$
\begin{array}{ll}
\frac{d r_{1}}{d t^{\prime}}=b_{1}\left(\overline{\mathrm{T}_{\mathrm{M}}}-r_{1}\right), & \left.\frac{d r_{2}}{d t^{\prime}}=b_{2} \overline{\left(\mathrm{T}_{\mathrm{M}}\right.} \mathrm{T}_{\mathrm{c}}-r_{2}\right) \\
\frac{d p}{d t^{\prime}}=b_{2}\left(\alpha r_{2}-\beta p\right) &
\end{array}
$$

Further let us assume for simplicity that $b_{1}=b_{2}=b$ and put $b t^{\prime}=t$ then we have

$$
\begin{aligned}
& \frac{d r_{1}}{d t}=\overline{\mathrm{T}_{\mathrm{M}}}-r_{1} \\
& \frac{d r_{2}}{d t}=\overline{\mathrm{T}_{\mathrm{M}}} \mathrm{T}_{\mathrm{c}}-r_{2} \\
& \frac{d p}{d t}=\alpha r_{2}-\beta p
\end{aligned}
$$

instead of $\left(5.1^{\prime}\right),\left(5.2^{\prime}\right)$ and $\left(5.3^{\prime}\right)$. Equation (5.4') can be transformed in

$$
\left.\begin{array}{ll}
\mathrm{T}_{\mathrm{c}}=1 & \text { when } r_{1} \geqq p \\
\mathrm{~T}_{\mathrm{c}}=0 & \text { when } r_{1}<p
\end{array}\right\}
$$

In our reduced mathematical model the unknown constants are only $\alpha$ and $\beta$. Their values are determined empirically so as to give a reasonable curve compared with experiment. However, we can assume that $\beta \ll 1$ or $\beta^{\prime} \ll \mathrm{b}_{2}$, i. e. the turnover rate of $R_{1}$ or $R_{2}$ is larger than that of protein. This is reasonable, because a messenger molecule cannot be expected to function, if its decay constant is small. In acoustics the information of our voice is disturbed by echo, if it does not decay adequately.

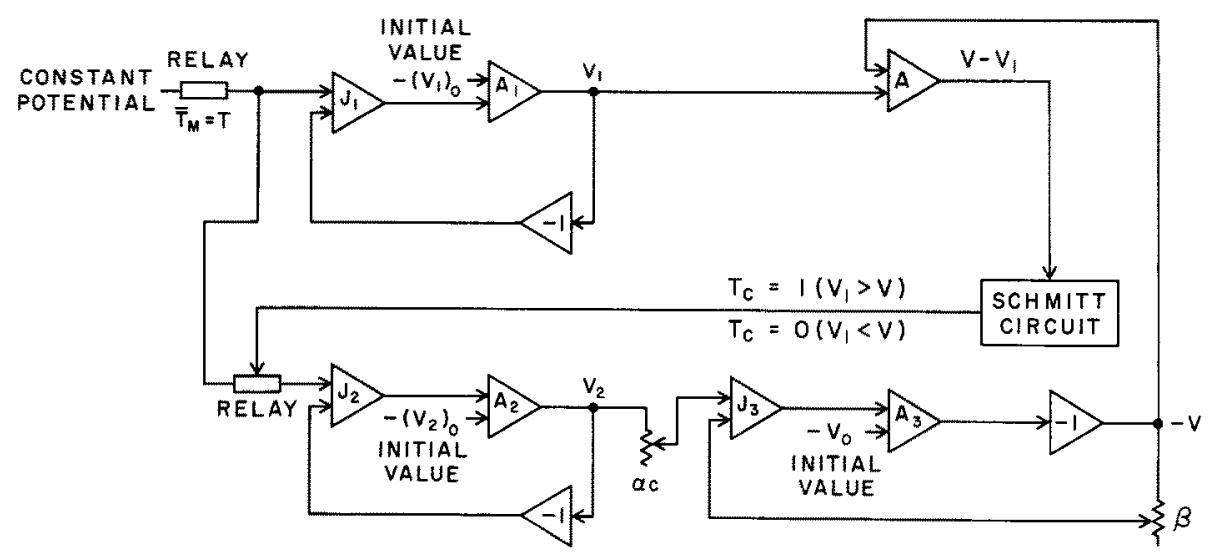

Fig. 11: Circuit diagram of analogue computer. This computer is used to solve the Equations (5.1), (5.2) and (5.3). Here $V_{1}, V_{2}$ and $V_{3}$ are used instead of $r_{1}, r_{2}$ and $p . J$ : integrator, $A$ : adder, -1 : sign changer. Schmirt circuit generates a signal current when $V_{1}-V>0$.

$\overline{\mathrm{T}}_{\mathrm{M}} \rightarrow 1$ signals the occurrence of mitosis and $\mathrm{T}_{M} \rightarrow 1$ its termination

Figure 11 demonstrates the block diagram of our analogue simulation; a ScHMITT trigger is used. The values $\alpha=0.1$ and $\beta=0.01$ were selected; the curves are not favourable for our purpose if other values of $\alpha$ and $\beta$ are assumed. Figure 12 is the 
result of our computation. The synthesis of $R_{2}$ ( $r_{2}$ curve) starts at $t_{1}$ after a short delay, as $r_{1}<p$ during the interval $t<t_{1}$. When $t \geqq t_{1}, r_{1}>p$ and $r_{2}$ tends to reach its saturation value, the curve of $p$ becomes nearly linear; i. e. $\frac{d p}{d t}$ is proportional to the saturation value of $r_{2}$. At $t=t_{2}, p=r_{1}$, then $r_{2}$ decays strongly and fluctuates, as $r_{1}-p$ fluctuates, although the amplitude is very small and $r_{1} \fallingdotseq p$ in rough approximation.

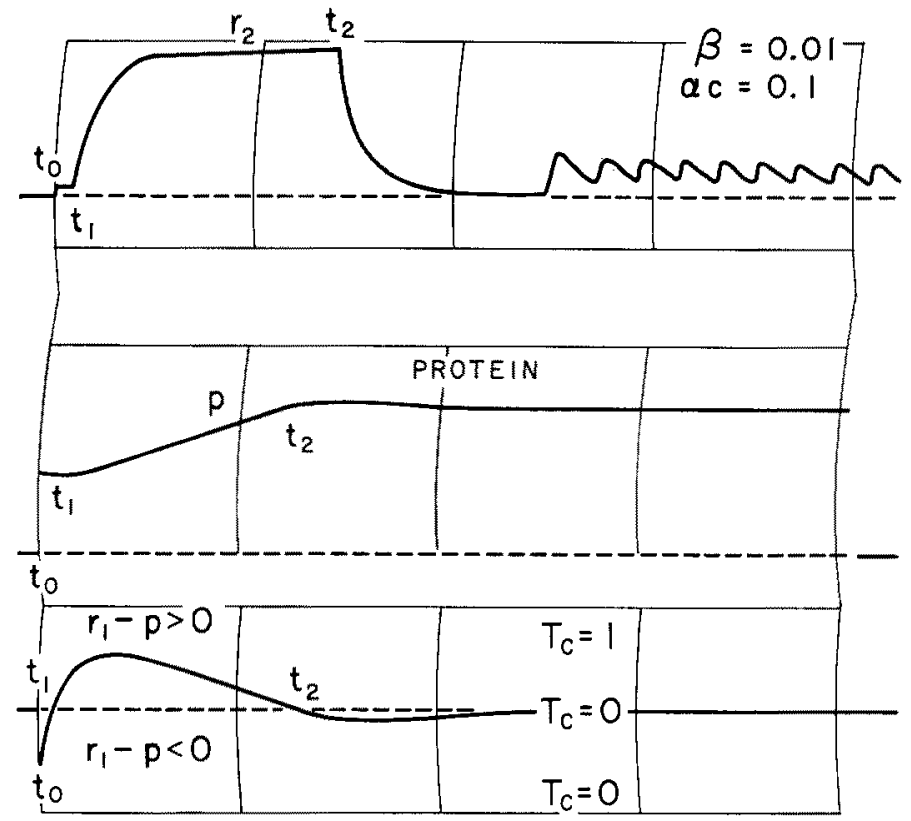

Fig. 12: Result of analogue computation. Solution of equations (5.1), (5.2) and (5.3) concerning $r_{1}, r_{2}$ and $p$ by analogue computation. From top to bottom: curve of $r_{2}$, protein, $p$, and $r_{1}-p$

\section{MATHEMATICAL MODEL OF CELL DIFFERENTIATION}

The idea of the molecular mechanism of cell differentiation proposed by MoNOD $\& \mathrm{JACOB}_{\mathrm{A}}(1961)$ is very suggestive. Figure 13 represents the logical circuit corresponding to this idea, Figure 14 the circuit of the ordinary flip-flop, in which redundancy is taken into account. Due to such a redundancy the action of the flip-flop may be stabilized.

YČAs, SUgITA \& Bensam (1965) have made suggestions concerning the role played by some controlling molecules, which may decay during mitosis. If the activity level of such molecules or regulatory metabolites drops below a certain level, one state of molecular flip-flop may be switched to another. Sugrta (1965a) has extended this idea and proposed the mechanism shown in Figure 15. The block diagram of the 


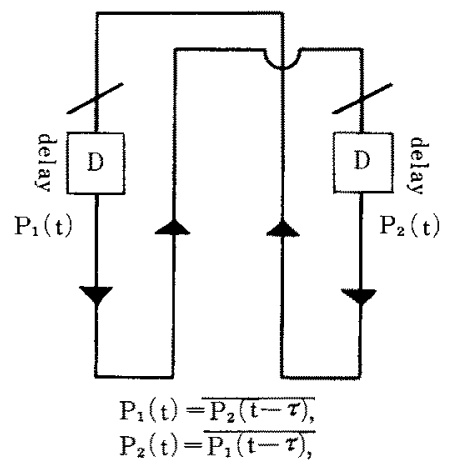

Fig. 13: Logical circuit of the model of MONOD \& JACOB (1961). $P_{1}(t)=\overline{P_{2}(t-t)} ; P_{2}(t)=$ $\overline{\mathrm{P}_{1}(t-\tau)}$; where $\tau$ is the delay

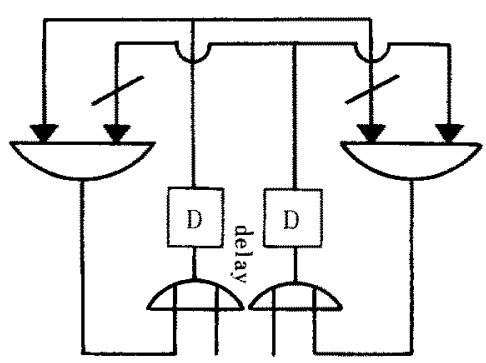

$$
\begin{aligned}
& P_{1}(t)=P_{1}(t-\tau) \overline{P_{2}(t-\tau)} \\
& P_{2}(t)=P_{2}(t-\tau) \overline{P_{1}(t-\tau)}
\end{aligned}
$$

Fig. 14: Logical circuit of flip-flop. $\mathrm{P}_{1}(t)=\mathrm{P}_{1}(t-\tau) \overline{\mathrm{P}_{2}(t-\tau)} ; \mathrm{P}_{2}(t)=\mathrm{P}_{2}(t-\tau) \overline{\mathrm{P}_{1}(t-\tau)}$; where $P_{1}(t-\tau)$ and $P_{2}(t-\tau)$ are redundant factors

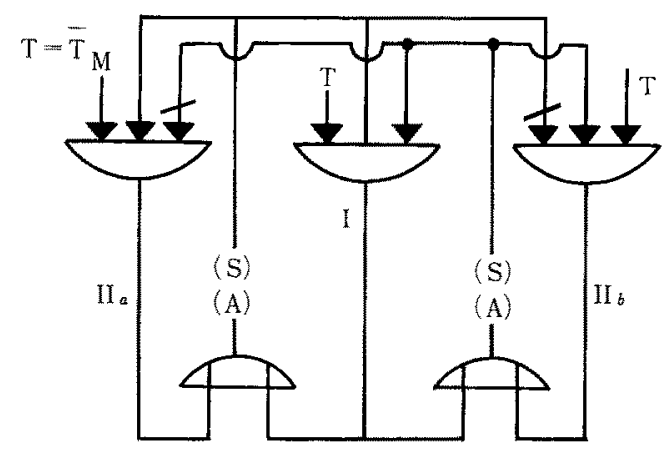

(A): analogue comp.

(S) : Schmitt circuit

Fig. 15: Proposed circuit of molecular flip-flop. (A) : analogue computer, (S) : ScHMrrt circuit 
analogue computer in the flip-flop circuit (A) has been drawn considering the following equation of kinetics:

$$
\left.\begin{array}{l}
\frac{d a}{d t}=\overline{\mathrm{T}_{\mathrm{MI}}} \mathrm{T}_{\mathrm{a}} A-k_{\mathrm{a}} a \\
\frac{d b}{d t}=\overline{\mathrm{T}_{\mathrm{M}}} \mathrm{T}_{\mathrm{b}} B-k_{\mathrm{b}} b
\end{array}\right\}
$$

where $a$ and $b$ are the quantities of the regulatory metabolites, $T_{M}$ is the signal of mitosis, $\mathrm{A}$ and $\mathrm{B}$ are respectively the rate of formation of $a$ and $b, k_{\mathrm{a}}$ and $k_{\mathrm{b}}$ are the decay constants, and $T_{a}$ and $T_{b}$ are the binary parameters satisfying the following conditions:

$$
\begin{array}{ll}
\mathrm{T}_{\mathrm{a}}=1 & \text { when } a \geqq a_{\mathrm{c}} \\
\mathrm{T}_{\mathrm{a}}=0 & \text { when } a<a_{\mathrm{c}} \\
\mathrm{T}_{\mathrm{b}}=1 & \text { when } b \geqq b_{\mathrm{c}} \\
\mathrm{T}_{\mathrm{b}}=0 & \text { when } b<b_{\mathrm{c}}
\end{array}
$$

$a_{\mathrm{c}}$ and $b_{\mathrm{c}}$ are critical values. The pulse $\mathrm{T}_{\mathrm{a}}=1$ or $\mathrm{T}_{\mathrm{b}}=1$ is generated by the SCHMITT trigger (S). Here also the system (A) - - (S) may correspond to a delay unit.

During mitosis $\mathrm{T}_{\mathrm{MI}}=1, \overline{\mathrm{T}_{\mathrm{MI}}}=0$, so that

$$
\frac{d a}{d t}=-k_{\mathrm{a}} a, \quad \frac{d b}{d t}=-k_{\mathrm{b}} b
$$

and $a$ and $b$ both decay. (i) If after mitosis $a \geqq a_{c}, b \geqq b_{\mathrm{c}}$, then $\mathrm{T}_{\mathrm{a}}=1, \mathrm{~T}_{\mathrm{b}}=1$ and $a$ and $b$ can be generated. Such a state may correspond to I of the flip-flop. (ii) If after mitosis $a \geqq a_{c}, b<b_{c}$, then $\mathrm{T}_{\mathrm{a}}=1, \mathrm{~T}_{b}=0$, so that $a$ is generated continuously, whereas $b$ is not. This may correspond to $\mathrm{II}_{\mathrm{a}}$. (iii) If $a<a_{c}$, and $b \geqq b_{c}$, then $\mathrm{T}_{\mathrm{a}}=0$

Fig. $16 a$

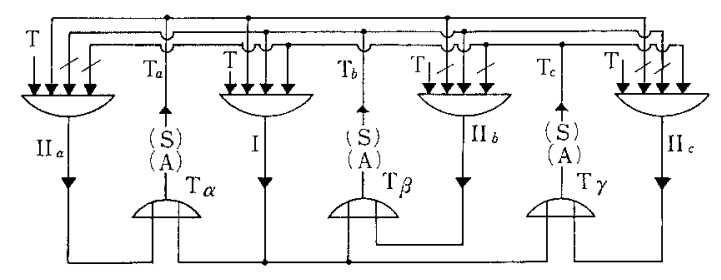

Fig. 16b

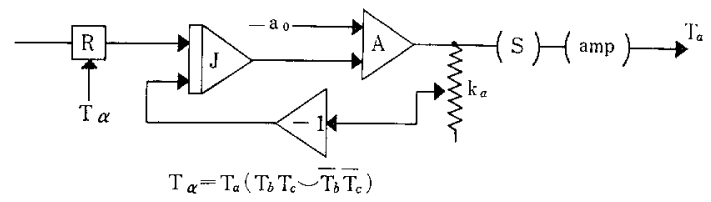

Fig. 16: (a) Logical circuit of flip-flop (three kinds of regulatory metabolites); (b) Circuit diagram of analogue computer

and $T_{b}=1$. Thus, $b$ is generated continuously whereas $a$ is not. This may correspond to $\mathrm{II}_{\mathrm{b}}$. State $\mathrm{I}$ may correspond to the undifferentiated state and $\mathrm{II}_{\mathrm{a}}$ and $\mathrm{II}_{\mathrm{b}}$ to the differentiated one. If, on the other hand, $a<a_{\mathrm{c}}$ and $b<b_{\mathrm{c}}$, such a cell cannot survive. 
In case of three kinds of controlling molecules, $(a, b$ and $c)$ being the quantities of the regulating metabolites we have instead of equation (6.1):

$$
\begin{aligned}
& \frac{d a}{d t}=\overline{\mathrm{T}_{\mathrm{M}}} \mathrm{T}_{\mathrm{a}}\left(\mathrm{T}_{\mathrm{b}} \mathrm{T}_{\mathrm{c}}+\overline{\mathrm{T}}_{\mathrm{b}} \overline{\mathrm{T}_{\mathrm{c}}}\right) A-k_{a} a \\
& \frac{d b}{d t}=\overline{\mathrm{T}_{\mathrm{M}}} \mathrm{T}_{\mathrm{b}}\left(\mathrm{T}_{\mathrm{c}} \mathrm{T}_{\mathrm{a}}+\overline{\mathrm{T}}_{\mathrm{c}} \overline{\mathrm{T}}_{\mathrm{a}}\right) B-k_{b} b \\
& \frac{d c}{d t}=\overline{\mathrm{T}_{\mathrm{M}}} \mathrm{T}_{\mathrm{c}}\left(\mathrm{T}_{\mathrm{a}} \mathrm{T}_{\mathrm{b}}+\overline{\mathrm{T}}_{\mathrm{a}} \overline{\mathrm{T}_{\mathrm{b}}}\right) C-k_{c} c
\end{aligned}
$$

where $T_{a}, T_{b}$ and $T_{c}$ satisfy the following conditions:

$$
\begin{aligned}
& \mathrm{T}_{\mathrm{a}}=1 \text { when } a \geqq a_{\mathrm{c}} \quad \mathrm{T}_{\mathrm{b}}=0 \text { when } b<b_{\mathrm{c}} \\
& \mathrm{T}_{\mathrm{a}}=0 \text { when } a<a_{\mathrm{c}} \quad \mathrm{T}_{\mathrm{c}}=1 \text { when } c \geqq c_{\mathrm{c}} \\
& \mathrm{T}_{\mathrm{b}}=1 \text { when } b \geq b_{\mathrm{c}} \quad \mathrm{T}_{\mathrm{c}}=0 \text { when } c<c_{\mathrm{c}}
\end{aligned}
$$

The logical circuit of the flip-flop is given in Figure 16. The molecular mechanism proposed by our circuit model is somewhat different from that of MONOD \& JACOB (1961) (Figure 17). In our model of Figure 18, $a$ is the inducer of $E_{A}$ and $E_{B A}$ and the

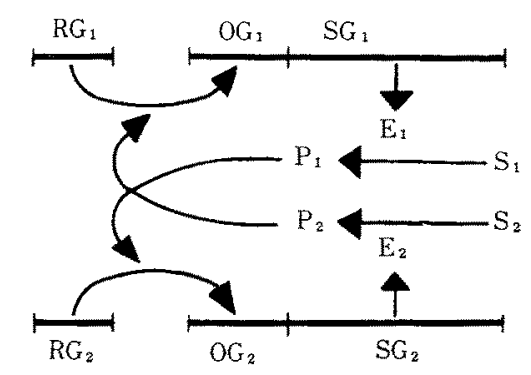

Fig. 17: Molecular mechanism considered by MONOD \& JACOB (1961)

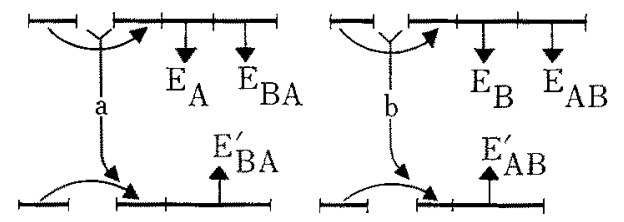

Fig. 18: Proposed mechanism of molecular flip-flop

$$
\langle a\rangle \stackrel{E_{A B}}{\longrightarrow} a^{\prime} \stackrel{E_{A}}{\longrightarrow} a . \quad\langle b\rangle \stackrel{E_{B A}}{\longrightarrow} b^{\prime} \stackrel{E_{A}}{\longrightarrow} \stackrel{E_{B}}{\longrightarrow} b
$$

Fig. 19: Kinetic model of regulatory metabolites

corepressor of $\mathrm{E}_{\mathrm{BA}}^{\prime}$ formation. Figure 19 illustrates a kinetic model of $a$ and $b$ formation. The enzyme has to be specific for each reaction, and there are 6 kinds of enzymes, i. e. $E_{A}, E_{B A}, E_{B A}^{\prime}, E_{B}, E_{A B}$, and $E_{A B}^{\prime}$. They are controlled simply by the 
regulatory metabolites $a$ and $b$. If the number of regulatory metabolites is 3 , we may consider the mechanisms of Figures 20 and 21 respectively. This is an extension of the idea of "one gene one enzyme". A simplification of the model considered is represented in Figure 22; the switching is not only due to the on-off nature of OG but also to the
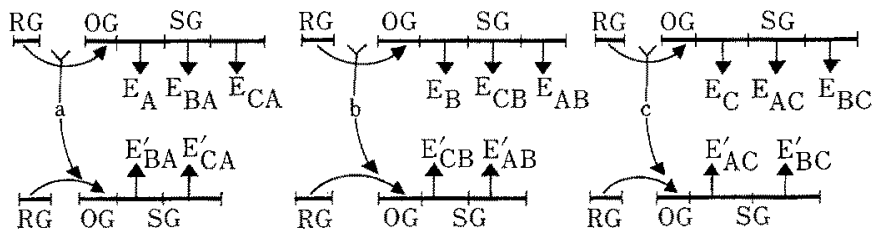

Fig. 20: Mechanism of molecular flip-flop (three kinds of regulatory metabolites)

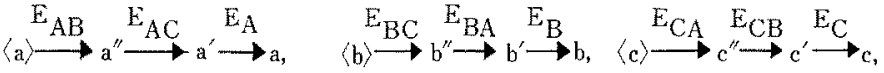

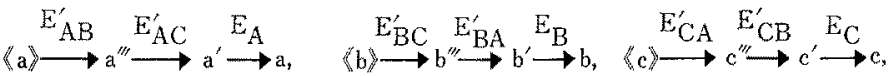

Fig. 21: Kinetic model (three kinds of regulatory metabolites)


Fig. 22: Simplified switching circuit model of the metabolite-formation

specific nature of enzyme reactions. The influence of existence or non-existence of the specific enzyme represented by a switching action, is illustrated in Figure 22 for the formation of $a, b$ and $c$. There is also a phenomenon of logical flip-flop in enzyme reaction like that of phosphofructokinase (GARFINKEL 1965). 
Let us introduce here binary functions $\mathrm{f}\left(r_{\mathrm{a}}\right), \mathrm{f}\left(r_{\mathrm{b}}\right)$ and $\mathrm{f}\left(r_{\mathrm{c}}\right)$, which are

$$
\begin{array}{ll}
\mathrm{f}\left(r_{\mathrm{k}}\right)=1 & \text { when } r_{\mathrm{k}} \geqq\left(r_{\mathrm{k}}\right)_{\mathrm{c}} \\
\mathrm{f}\left(r_{\mathrm{k}}\right)=0 & \text { when } r_{\mathrm{k}}<\left(r_{\mathrm{k}}\right)_{\mathrm{c}}
\end{array}
$$

Then we can say that the variation of the pattern of $f\left(r_{\mathrm{a}}\right), f\left(r_{\mathrm{b}}\right)$ and $f\left(r_{\mathrm{c}}\right)$ may have an important meaning: a clearcut change of this pattern may correspond to the transition

Table 1

\begin{tabular}{|c|c|c|c|c|c|c|c|c|c|}
\hline & $a$ & $b$ & $c$ & $f\left(r_{a}\right)$ & $\mathrm{f}\left(\mathrm{r}_{\mathrm{b}}\right)$ & $f\left(r_{e}\right)$ & $\mathrm{T}_{\mathrm{a}}$ & $T_{b}$ & $\mathrm{~T}_{\mathrm{e}}$ \\
\hline I & $a \geqq a_{0}$ & $b \geq b_{0}$ & $c \geq c_{c}$ & 0 & 0 & 0 & 1 & 1 & 1 \\
\hline $\mathrm{II}_{\mathrm{a}}$ & $a \geqq a_{0}$ & $b<b_{c}$ & $c<c_{c}$ & 0 & 1 & 1 & 1 & 0 & 0 \\
\hline $\mathrm{II}_{\mathrm{b}}$ & $a<a_{0}$ & $b \geq b_{c}$ & $c<c_{0}$ & 1 & 0 & 1 & 0 & 1 & 0 \\
\hline $\mathrm{II}_{\mathrm{c}}$ & $a<a_{0}$ & $b<b_{0}$ & $c \geqq c_{\mathfrak{C}}$ & 1 & 1 & 0 & 0 & 0 & 1 \\
\hline
\end{tabular}

Change of pattern corresponding to the transition I $\rightarrow$ IIa etc.

$\mathrm{I} \rightarrow \mathrm{II}_{a}$ etc (Table 1 ). In this case the genetic pattern, i. e. the base sequence of DNA, may be the same during cell life.

From the view-point of biology, on the other hand, there is a serious problem concerning differentiation, e. $g$. the problem of motivation of the transition, $I \rightarrow I_{\mathfrak{a}}$, and of its irreversibility. If the differentiation is based on a movement of the pattern of $\mathrm{f}\left(r_{\mathrm{a}}\right), \mathrm{f}\left(r_{\mathrm{b}}\right)$... we must search for the mechanism of such a movement. Heterogeneity of the ovum, for instance, may be triggered by the metabolites $a, b, \ldots$ and thus influence the flip-flop. The $\mathrm{CO}_{2}$ level or $\mathrm{pH}$ value may also influence the flip-flop. YČAS, SUGITA \& BENSAM (1965) have discussed this matter but have not yet arrived at decisive conclusions.

The mathematical model considered here may be more suitable than that of Monod \& JACOB (1961). The new model cannot be the only conclusive one; more suitable ones do exist. However, all other models must be logically equivalent to the model considered above. Since many equivalent circuits could be introduced (Sugrta \& Fukuda 1963), we have to select the most appropriate one.

\section{CONCLUDING REMARKS}

\section{Continuous analysis and automaton theory}

The information of DNA is primarily recorded in form of the base sequence A, T, C, G, but according to the pattern $f\left(r_{1}\right), f\left(r_{2}\right), \ldots$ it may be active or inactive. This sequence represents the state of DNA, dependent of whether the loci corresponding to $k$ are readable or not. Differentiation may be realized by a rather permanent change of this sequence. In addition, there may be another temporal sequence change important in cell physiology, i. e. enzyme induction or repression.

DNA may correspond to the tape of the TURING-machine, the full information of which may not only be represented by a genetic one, expressed as base sequence, 
but also by the pattern $\mathrm{f}\left(\gamma_{\mathrm{k}}\right)$, that is, the information describing whether the genetic one is readable or not. The former is permanent except in the case of mutation; however, the latter can be stored on tape anew as well as be erased rather easily and may be processed by the molecular automaton. The phenotype nature may be controlled by such an information processing concerning $\left[f\left(r_{k}\right)\right]$. On the other hand, the genotype nature may be due to the base pattern of DNA.

In the introduction to this paper the probable limit of the continuous analysis was outlined. If $F(x)$, for instance, is an increasing function of $x$, then $F(x)$ decreases when $x$ decreases. Let us consider the function $F(x) \overline{f(x)}+G(x) \mathrm{f}(x)$, where $\mathrm{f}(x)=0$ when $x<x_{\mathrm{c}}$ and $\mathrm{f}(x)$ is changed irreversibly to 1 , if $x$ once exceeds the threshold value $x_{0}$ and this function, which was at first $F(x)$, behaves in the form $G(x)$. Such a behaviour may be observed in many living systems as well as in physics e. g. in hysteresis. If we put

where

and

$$
\begin{aligned}
& \mathrm{f}\left(x_{\mathrm{t}}\right)=\overline{\mathrm{f}\left(x_{\mathrm{t}-\tau}\right)} \delta_{1}\left(x_{\mathrm{t}}\right)+\mathrm{f}\left(x_{\mathrm{t}-\tau}\right) \delta_{2}\left(x_{\mathrm{t}}\right) \\
& \delta_{1}(x)=1 \quad \text { when } x \geqq x_{\mathrm{c}} \\
& \delta_{1}(x)=0 \quad \text { when } x<x_{\mathrm{c}} \\
& \delta_{2}(x)=1 \quad \text { when } x \geqq x_{\mathrm{c}}^{\prime} \\
& \delta_{2}(x)=0 \quad \text { when } x<x_{\mathrm{c}}^{\prime} \\
& x_{\mathrm{e}}^{\prime}<x_{\mathrm{e}}
\end{aligned}
$$

then $\mathrm{f}\left(x_{\mathrm{t}}\right)$ shows a hysteresis curve, where $x_{\mathrm{t}}$ is the value of $x$ at the time $t$. Therefore, $F(x) \overline{f(x)}+G(x) f(x)$ shows a two valued function in the domain $x_{0}^{\prime} \leqq x \leqq x_{0}$. In many cases a quantitative change may have a threshold value and generate a qualitative one, which is registered in a digital way. This is the reason why this matter cannot be handled by continuous analysis alone. It is only one type of approximation and the finite analysis another. Also the last mentioned reveals limits of its applicability, therefore, a hybrid computing or analysis has been proposed.

\section{Energy and entropy of activation}

Energy is needed for transmission as well as for parametric action of information. Valve action energy is required for valve opening. If a tank is equipped with a valve, then the energy to generate the jet (response), on the contrary, is due to the potential energy of the water in the tank. In a chemical reaction the flux of the rate process is due to the free energy of this system and represents the response of this system. On the other hand, the energy of activation may in some cases be supplied by information. If so, the parametric action of the information may be due to this energy supply (in which ATP may play a role).

However, the parametric action of DNA in mRNA formation or of mRNA in protein synthesis on the ribosome level is somewhat different. In the mRNA formation ribonucleoside triphosphates produce a complex with a base sequence according to that of DNA. If such a complex were arranged without the influence of the H-bond of DNA, then the probability of having the necessary base sequence would be very small. The $\mathrm{H}$-bond between a nucleotide of DNA and a ribonucleoside may stabilize 
the complex similar to the situation in an ice crystal, in which the state of small entropy is also stabilized by the $\mathrm{H}$-bond. In the case of mRNA formation entropy of activation is due to the base sequence of DNA. Therefore, a close relation between negative entropy of information and entropy of activation can be recognized. The energy of the nucleoside triphosphates may play a role as energy source for activation. Therefore for this process both entropy as well as energy of activation are required.

There are many types of coupling in chemical reactions. In a chemical cycle a reaction-product may be re-used as precursor of another reaction. Such re-use represents a material coupling. Another type of coupling is that between endergonic and exergonic reactions, e. g. $\mathrm{S} \rightarrow \mathrm{P}$ and $\mathrm{ATP} \rightarrow \mathrm{ADP}$. These couplings are direct ones. In

addition, there are also indirect couplings, e. g. $\mathrm{A} \stackrel{\mathrm{E}}{\rightarrow} \mathrm{P}$ and $\mathrm{D} \rightarrow \mathrm{E}$ or $\mathrm{E} \rightarrow \mathrm{E}^{\prime}$; the flux of $\mathrm{D} \rightarrow \mathrm{E}$ or $\mathrm{E} \rightarrow \mathrm{E}^{\prime}$ may correspond to the signal current of an electrical communication (SugITA 1961a).

\section{APPENDIX I}

\section{Thermodynamics of open systems}

From the thermodynamical point of view living things are quite similar to a siphon through which water of a tank flows out. This siphon is an open system, the function of which is maintained by the flux of water itself, just like the function of the living organism, which is maintained by metabolism. In considering this phenomenon the level of tank-water is of greatest importance, because the siphon cannot work, unless the level of water is high. This situation is similar to the most important prerequisite for the existance of life, namely, that our earth is provided with higher free chemical energy, the living organisms representing the "pathways" of free energy consumption.

It seems at first to be against the law of hydrodynamics that water ascends through a branch of the siphon; but this of course is due to the coupling with the descending water in another branch, just like the metabolic dynamo of an organism. Thus, the state of water at the top of the siphon may correspond to that of the lower entropy (higher free energy) level.

The most prominent feature of life, however, may be the parametric control, by which the rate of irreversible processes is determined. "Vital force" or "entelechy" have frequently been discussed but nothing is able to promote the reactions against the laws of thermodynamics. Only the rate of realization of this latent possibility, which may be determined thermodynamically, can be influenced by the function of life, i. e. triggered or inhibited by information and control. This and thermodynamics of flux systems will be discussed further in Appendix III.

According to the phenomenological theory of thermodynamics, fluxes are driven by intensive factors, which may be of thermodynamic nature, e. g. the field of a chemical potential. From the molecular point of view, however, these fluxes must be of a very complicated nature, and it may only be possible in some special cases to adopt them as being proportional to the intensive factors. Do the processes in living systems parallel such cases, even though they deviate significantly from the thermo- 
dynamical equilibrium? Still worse organisms are strongly heterogeneous, but we must take into account a small number of molecules (HrLL 1963, 1964). It seems rather striking that a chemical or electro-chemical potential (redox potential) may assume the role of the intensive factor, e. g., in the case of membrane permeation.

The fluid model tani corresponds to a compartment, the pipes connecting the tanks to the pathways of the metabolic map. From the thermodynamical point of view the term "compartment" describes a region within which all sites possess the same chemical potential and the same functional form. The smaller the region, the greater is the fluctuation in number of particles having the same chemical potential, since the system is not closed. However, fluctuation may not be the fundamental aspect of life; there may be some kind of mechanism which is able to stabilize the molecular state against fluctuation, making the grouping (coarse graining) of variables possible. This matter will be the topic of a future theoretical study, the theory of small systems.

Within a flux system there are two types of reaction coordinates (page 81). Along the quasi-equilibrium coordinate chemical potentials or any other intensive factors vanish. Along the flux coordinate the field is of finite strength, and entropy production occurs. In special cases the flux is zero, although the field of the intensive factor has a finite strength (frozen state).

Consider an interval $\delta t$, during which the flux $J_{\mathrm{i}} \delta t$ can be neglected, then the transition of matter along the flux coordinate can be artificially, neglected or frozen in and each compartment can be considered in equilibrium, and, in the case of fluorescence for instance, the excited state may also be considered a compartment. In such a situation $\delta t$ must be shorter than the life time of the electronic state, a triplet state for example. Therefore, if a certain group of chemical reactions or quantum transitions in the organism can be considered frozen, the corresponding chemical or quantum states make compartments, e. g. high energy, low entropy or free radical states.

From the perspective of statistical mechanics, the pseudo-equilibrium considered here may correspond to a certain part in the phase space. Then the other part of this super-space can be neglected during $\delta \mathrm{t}$ in considering the partition function (SucrTa 1957b). Free energy of such a flux system can thus be considered as an idea, although its explicit form is difficult to determine theoretically from the partition function. In practice, it may be determined empirically or phenomenologically.

In small systems virtual force, corresponding to the fluctuation, has to be added to the field of chemical potential - a kind of mean value of the fluctuating force in space and time as in the LANGEvin equation of Brownian movement. There may be fluctuations of the reaction at the DNA level (rate of mRNA formation, for instance); however, such fluctuations may be cancelled at the ribosome level, e. g. at the enzyme formation level'. Then the reaction catalyzed by the enzyme may be rather steady (Fig. 12) and fluctuation may not be the essential feature of life.

${ }^{1}$ The fluctuation at the DNA level may in exceptional cases be stronger than the Brownian movement; the information of DNA would then be comparable to a commander giving orders in a noisy environment. The logical circuit may still function although conveying errors with certain probability. We are confronted here on the one hand, with an interesting field of mathematics and, on the other, with important biological problems including cancer origin. 
At this point we introduce the idea of a quasi-equilibrium condition:

$$
(\delta G)_{\mathrm{fr}} \geqq 0
$$

where the variation of the variables concerning the flux coordinates are frozen (suffix fr), and only variations concerning quasi-equilibrium coordinates are taken into account. In regard to a membrane, for instance, $\delta n\left(\mathrm{Na}^{+}\right)=0$, as $n\left(\mathrm{Na}^{+}\right)$is the quantity of $\mathrm{Na}^{+}$and the quantity of the flux coordinate (assuming the presence of a sodium pump) but $\delta n(\mathrm{Cl}-) \neq 0$. Therefore the quasi-equilibrium condition for $\mathrm{Cl}-$ is obtained from equation (1), and the equation of the DONNAN potential is derived as purely logical (SugrTA 1957b).

On the other hand, $d n_{\mathrm{j}} / d t$ in $d G / d t$ must be the rate of change concerning the flux coordinate, where $G(t)$ is the value of Gibbs free energy, which is a function of $t$, because $G(t)$ and $G(t+\delta t)$ may respectively correspond to different parts of the phase space at $t$ and $t+\delta t$. Therefore,

$$
\frac{d G}{d t}=\left\{\frac{\Delta G}{\Delta t}\right\} \Delta t<\delta t
$$

where $\delta t$ is larger than $\Delta t$ but small in macroscopic scale. This quantity can be expressed by entropy production. The idea of the frozen equilibrium is important in defining free energy and chemical potential of a dynamical system. If we compute the partition function of every partial system in quasi-equilibrium, the product of the partition function of every partial system may be the partition function of the total dynamical system. In this case $\delta t$ may be determined considering the order of $J_{i} \delta t$, where $J_{i}$ is the flux of the flux coordinate $\mathrm{i}$. The reaction coordinate is a kind of flux coordinate. If $J_{i} \delta t$ becomes negligible, the difference of the quasi-equilibrium state from the true equilibrium may also be negligible. Considering thermodynamically we have

$$
\frac{d G}{d t}=\overrightarrow{g_{1}}-\overrightarrow{g_{2}}-W-D
$$

where $G$ is Gibbs free energy of the organism, $\overrightarrow{g_{1}}$ and $\overrightarrow{g_{2}}$ are respectively the influx and outflux of free energy, $W$ is the free energy consumption for doing the work $W_{\mathrm{L}}$ externally and $D$ is the consumption due to other irreversible processes. $W$ can be written in

$$
W=W_{L}+W_{f}
$$

where $W_{L}$ is the outflux of the work and $W_{\mathrm{f}}$ is the internal loss accompanying $W_{\mathrm{L}}$. Then

$$
\frac{W_{\mathrm{f}}+D}{T}
$$

is the entropy production in this organism. The balance of entropy of this open system is expressed by

$$
\frac{d S}{d t}=\overrightarrow{s_{1}}-\overrightarrow{s_{2}}+\frac{Q_{a}}{T}+\frac{W_{\mathrm{f}}+D}{T}
$$

where $S$ is the entropy of the organism, $\overrightarrow{s_{1}}$ and $\overrightarrow{s_{2}}$ are respectively influx and outflux 
of the entropy flux and $-Q_{a}$ is the outflow of heat from the organism (Sugrta 1955). In the same way we have

$$
\frac{d \chi}{d t}=\overrightarrow{\chi_{1}}-\overrightarrow{\chi_{2}}-W_{\mathrm{L}}-\mathrm{Q}_{\mathrm{a}}
$$

where $\chi$ is the heat function (enthalpy) of this organism and $\overrightarrow{\chi_{1}}$ and $\overrightarrow{\chi_{2}}$ are respectively the influx and the outflux of enthalpy of this organism. This equation is important in considering the energy balance of an organism. In regard to the external system building up the environment of this organism the free energy of the environment may be determined by

$$
\frac{d G_{\mathrm{a}}}{d t}=-\overrightarrow{g_{1}}+\overrightarrow{g_{2}}+W_{\mathrm{L}}
$$

Then the free energy of the total system, i. e. the total free energy of this system and of its environment, is $G+G_{\mathrm{a}}$. The change of this total free energy is given by equations (3) and (8)

$$
\frac{d}{d t}\left(G+G_{a}\right) \leqq 0
$$

coinciding with the ordinary theory of thermodynamics. Equation (3) and its application to biological systems was described by SUgITA (1954).

\section{APPENDIX II}

\section{Maximum Principle}

A generally accepted opinion states that in a living system several quantities may reach a maximum value. Sugr't (1953) has pointed out that the absolute value of (9), i. e.

$$
\left|\frac{d G}{d t}+\frac{d G_{\mathrm{a}}}{d t}\right|
$$

may assume the maximum value and that such a principle might be an extension of thermodynamics; however, he has now changed his opinion. If such a principle holds true, it must be a result of natural selection or a similar biological principle and cannot be a simple extension of a principle of physics. In transient phenomena the possibility of complex growth of small entropy or of large free energy, promoting rates of transition, arises. For example, the activated complex of a rate process with considerable energy of activation promotes the chemical reaction rate; according to VoLMER (1938) crystal growth does not necessarily tend to the state of minimum free energy. Therefore an ordinary crystal has more free energy than one in thermodynamical equilibrium; the form with more free energy depends on the conditions of crystal growth. The snow flake is not stable; its molecules sublime from the nibs. The molecules condense again on the flake stem and finally produce a small ice block with small amounts of free energy. In the "Institute of Low Temperature Sciences" of the 
Hokkaido University in Japan, a snow flake in oil has been preserved for a few years at low temperature. Without oil it would be impossible, even at low temperature, to maintain its crystal form having more free energy or a lower entropy level. Volmer (1938) further mentioned the "Stufenregel", according to which the unstable second phase has more free energy than that of the stable one and, being unstable, is formed within the first phase, which is in the state of "Uberschreitung". This is reasonable from the view-point of the theory of rate processes.

A comparison between the history of a snow flake and the history of the organisms on the earth reveals interesting analogies. The snow flake may be visualized as a metabolic pathway by which the free energy of the supersaturated state is consumed. In the living organism the state of low entropy or high free energy is generated by the metabolic pump. The growth of the low entropy level is driven by the free energy of "Uberschreitung", which may correspond to the nutritive value of the organisms. As outlined above the low entropy state of organisms does not contradict the thermodynamical principle (SugiTa 1951).

The author has previously considered that the rate process takes the optimal path, by which the maximum rate of free energy utilization may be anticipated in order to promote rate processes more efficiently. He considered this to be a new principle of thermodynamics and on this basis he tried to explain the phenomena of life (SUGITA 1957b). This principle may physically be related to the principle of minimum production of entropy of PRIGOGINE or to the maximum principle of ONSAGER, although there are some logical differences as is well known. The author has changed his mind, because there are feedback systems in which such principles may not be valid; this was suggested by DeNBIGH (1952), who showed that there is a possibility of permanent oscillation instead of steady flow. Such an oscillation was discussed also by Sugita (1961b). On the other hand, there are important works of Prigogine \& BALEsCu (1955) concerning the non-equilibrium system where the principle of minimum production of entropy is not valid. In their treatment nonlinearity is taken into account. This field of research is so important that further development is anticipated.

In mathematical terms a living organism can be represented by a system of simultaneous differential equations of kinetics in the following form

$$
\frac{d n_{\mathrm{i}}}{d t}=\sum_{\mathrm{j}} J_{\mathrm{ji}}-\sum_{\mathrm{k}} J_{\mathrm{ik}}
$$

where $n_{\mathrm{i}}$ is the quantity of a substance of the compartment $i, J_{\mathrm{j} \mathrm{i}}$ is the flux from the compartment $j$ to $i$, and the like is with $J_{\mathrm{ik}}$. Then

$$
\frac{d G}{d t}=\sum_{\mathrm{n}} \sum_{\mathrm{i}} \mu\left(n_{\mathrm{i}}\right) \frac{d n_{\mathrm{i}}}{d t}
$$

where $\quad \mu\left(n_{\mathrm{i}}\right)=\frac{\partial G}{\partial n_{\mathrm{i}}}$

is the chemical potential of $n_{\mathrm{i}}$ in the compartment $\mathrm{i}$.

In mathematical biology stability and optimization of the metabolic system represented by equation (11) are discussed. However, there are two problems to be 
considered separately. The first one is the problem of non-linearity. In mathematical terms a system represented by non-linear differential equations is, in many cases, a feedback system; consequently, the differential equation (10) has to be non-linear. Thus the discussion based upon the ordinary theory of irreversible thermodynamics, taking into account only small deviations from equilibrium, cannot be valid. As was already mentioned by ELSASSER (1958), a parametric interaction cannot be expected in a system with only small deviations from thermodynamical equilibrium. The second problem is even more complicated. The fundamental problem to be discussed in biology is how to explain the generation of complicated non-linear systems. The origin of life as well as the development of an embryo can only be discussed on the basis of a development of non-linear systems with feedback control. While presentday mathematical theories deal adequately with the nature of a given mathematical model, the concept of the generation and development of such a model exceeds the scope of existing means.

\section{APPENDIX III}

\section{Information theory and cybernetics}

Parametric action caused by variation of the throttling factors is very important in biology: a large scale system can thus be realized through an adequately processed interaction. Within a mechanism of the old type, no "freedom" of information processing is contained; this leads to determinism as one way of thinking (SUGITA 1965b). Yet the idea of equifinality brings about concepts directly opposed to determinism. Transmission of parametric action has to be carried by material like a hormone; it therefore requires energy, which, as such, is different from the one needed for response, the latter necessarily being larger than the former. From this point of view, information offers its services as a kind of physical action and thus has to have a physical background.

In formal information theory, however, this background is conceptually neglected; only the degree of the complexity of the pattern or the time series is discussed. The degree of complexity is measured in "bit" units and is called the quantity of information or the negative entropy. The pattern of a signal has to be accompanied by a certain meaning; however this very meaning is extracted, and only the frequency of the appearance of the pattern is considered as a stochastic process (see also page 86). We must not confuse information as a physical pattern with parametric action, and information as the abstract idea considered in the information theory.

The main differences between bio-cybernetics and bio-mathematics are: (1) $\mathrm{Cy}$ bernetics is considered essentially as a finite system; otherwise it would hardly be possible to construct a simulator having finite elements. (2) The mathematical structure of cybernetics confines itself primarily to differential or difference-differential equations. Another aspect of cybernetics is the automaton theory (the set of discrete states may be a logical function of the pulse input generated by the continuous system as well as of those which are the output of other automata) (Sugrita 1966b). If 
the use of a simulator is taken into consideration, bio-cybernetics is a far narrower viewpoint than bio-mathematics.

Generally speaking, the scope of cybernetics is as limited as that of information theory because any consideration of the background (latent physical possibility) is put aside leaving parametric control as the mainly treated problem. Moreover, the idea of development or evolution may be an antithesis to a strictly cybernetic concept; it certainly is not easy to comprehend a development of the circuit model, whether it be a digital or analogue one. Such a limitation could be overcome by use of an adequate hybrid computing system into which many kinds of models are programmed. At a critical stage of computation, the system could change from one model to another. In order to formulate a mathematical model, we have to simplify the metabolic pathways, whereby some compartments must be grouped together.

\section{SUMMARY}

1. A differential equation of the kinetics of metabolic systems is formulated

$$
\frac{d n_{\mathrm{i}}}{d t}=\sum_{\mathrm{j}} J_{\mathrm{ji}}-\sum_{\mathrm{k}} J_{\mathrm{ik}}
$$

where $n_{\mathrm{i}}$ is the quantity of a metabolite in a compartment $i, J_{\mathrm{ji}}$ the influx from $j$ to $i$ and $J_{\text {ik }}$ the outflux from $i$ to $k$.

2. The fluxes $J_{\mathrm{ji}}$ or $J_{\mathrm{ik}}$ can be described as the product of throttling factor $X$ intensive factor. The thermodynamical nature of the intensive factor is considered and the idea of quasi-equilibrium introduced.

3. The notion of parametric action is outlined. Rate processes concerned with the flexibility of the throttling factor are considered as transmission of information; this facilitates an investigation of the parametric interaction or informational correlation in chemical reaction systems.

4. The flexibility of the throttling factor reveals that the equation of kinetics is nonlinear. Any feedback system has to be represented by such non-linear equations.

5. There are some cases in which non-linear behaviour may be represented approximately by a step-function; therefore, finite theory may be useful in such systems.

6. Since the limit of applicability of the continuous analysis based on differential equations of kinetics is well appreciated, binary functions or parameters are introduced into the equation of kinetics in order to unify the two types of analysis, finite and continuous. A hybrid computing system is used for this purpose.

7. Kinetics of $m R N A$ and repressor formation is especially considered and an appropriate hybrid system suggested. In simplifying this system the switching circuit model proposed previously is obtained.

8. A mathematical model of cell differentiation is proposed. A flip-flop circuit is assumed, composed of reactions at the genetic and other levels under the influence of inducible enzymes. The continuous kinetics in this model cell may function only under the control of such a molecular automaton.

9. A pattern of active (1) or inactive (0) states of DNA (101001 ...) may be superimposed upon the information at the genetic level. Cell differentiation is the 
most striking and permanently lasting variation of this pattern. In addition, temporal variations (repression and induction; open or closed states) which may be of physiological significance, are considered.

10. Energy for parametric action must be distinguished from energy for the response. The relation between entropy of activation and negative entropy of information, e. g. of DNA, is discussed.

11. In the appendices (I to III) thermodynamics of an open system are discussed; a thermodynamical function, such as a chemical potential in a dynamical system, is logically defined. Finally, the maximum principle and the importance of cybernetics are discussed.

\section{LITERATURE CITED}

Bellman, R., 1965. Mathematical problems arising in biomedical research. In: Digest of the 6th Intern. Conference on Medical Electronics and Biological Engineering, Japan. Soc. of Med. Electr. and Biol. Engng., Shinbashi, Minato-ku, Tokyo, 412-413.

- Gluss, B. \& Rотн, R., 1964. On the identification of systems and the unscrambling of data: some problems suggested by neurophysiology. Proc. natn. Acad. Sci. U.S.A. 52, 1239-1240.

DenbIGH, K. G., 1952. Entropy creation in open reaction systems. Trans. Faraday Soc. 48, 389-394.

ELSASSER, W. M., 1958. The physical foundation of biology. Pergamon pr., London, 219 pp.

GARFINKEL, D., 1965. A simulation study of mammalian phosphofructokinase. Scient. Mem. Inf. Exchange Grp. 3, No. 9, 1-8.

Glasstone, S., Laidler, K. J. \& Eyring, H., 1941. The theory of rate processes. McGrawHill, New York, 611 pp.

Goodwin, B. C., 1963. Temporal organization in cells. Acad. pr., New York, 163 pp.

Heinmets, F., 1964a. Analogue computer analysis of a model system for the induced enzyme synthesis. J. theor. Biol. 6, 60-70.

- 1964b. Elucidation of induction and repression mechanisms in enzyme synthesis by analysis of model system with the analog computer. In: Electronic aspects of biochemistry. Ed. by B. Pullman. Acad. pr., New York, 415-479.

- 1966. Cellular growth, injury and death. Mathematical formulation and analog computer analysis. Helgoländer wiss. Meeresunters. 14, 168-194.

Hess, B. \& Brand, K., 1966. Kontrollmechanismen der Glycolyse. Helgoländer wiss. Meeresuntersuchungen 14, 129-147.

HrLl, T. L., 1963. Thermodynamics of small systems. Benjamin, New York, pt 1, 1-183.

- 1964. Thermodynamics of small systems. Benjamin, New York, pt 2,1-222.

Horiuchi, T., 1961. A temperature sensitive regulatory system. J. molec. Biol. 3, 703-704.

- \& Novick, A., 1961. A thermolabile repression system. Cold Spring Harb. Symp. quant. Biol. 26, 247-248.

LuCAS, H. C. (Ed.), 1962. The Cullowhee conference on training in biomathematics. Institute of Statistics of North Carolina State College, Raleigh, N. C., 390 pp.

Monon, J. \& JАСОв, F., 1961. General conclusion: Teleonomic mechanisms in cellular metabolism, growth and differentiation. Cold Spring Harb. Symp. quant. Biol. 26, 389-401.

Онкі, S., 1965. Rectification by a double membrane. J. phys. Soc. Japan 20, 1674-1685.

PARDEE, A. B., JACOB, F. \& MONOD, J., 1959. The genetic control and cytoplasmic expression of inducibility in the synthesis of $\beta$-galactosidase by E. coli. J. molec. Biol. 1, 165-178.

Prigogine, I. \& Balescu, R., 1955. Sur les propriétés différentielles de la production d'entropie. 2. Bull. Acad. r. Belg. Cl. Sci. (Série 5) 41, 917-928.

StAHL, W. R., 1965a. Algorithmically unsolvable problems for cell automata. J. theor. Biol. 8, 371-393.

- 1965b. Self-reproducing automata. Perspect. Biol. Med. 8, 373-391. 
Sugrta, M., 1951. Thermodynamical method in biology. Ann. Hitotsubasbi Univ. (Suppl.) 1, 9-21.

- 1953. Thermodynamical analysis of life. 2. The maximum principle of transient phenomena. J. phys. Soc. Japan 8, 704-709.

- 1954. Mathematical analysis of the metabolism and analogy of economics. Ann. Hitotsubasbi Univ. 4, 163-182.

- 1955. The metabolic turnover and the maintenance of the low entropy level. J. pbys. Soc. Japan 10, 316-317.

- 1957a. Membrane equilibrium and quasi-equilibrium (in Japanese). Kagaku (Sci.) 27, 416.

- 1957b. Thermodynamics and molecular statistics (in Japanese). Nankodo, Tokyo, $248 \mathrm{pp}$.

- 1958. Informational correlation in irreversible processes and the application of this idea to biology (in Japanese). Bull. Kobayasi Inst. phys. Res, 8, 159-173.

- 1961a. Functional analysis of chemical systems in vivo using a logical circuit equivalent. J. theor. Biol. 1, 415-430.

- 1961b. Feedback mechanism of chemical system from the viewpoint of information technology. Prog. theor. Pbys., Kyoto (Suppl.) 17, 143-161.

- 1963. Functional analysis. 2. The idea of molecular automaton. J. theor. Biol. 4, 179-192.

- 1965a. Kinetic theory and mathematical model of cellular metabolism. (Preliminary report.) A. Rep. Res. Grp Biophys. Japan. 4, 43-59 (Stereotyped).

- 1965b. Fundamental idea of cybernetics: The idea of pure cybernetics and of cybernetic sciences. Hitotsubashi J. Arts Sci. 6, 45-73.

- 1966a. Hybridization of finite and continuous analysis. A. Rep. Res. Grp Biophys Japan 5, $17-29$.

- 1966b. Functional analysis. 4. Simulation of cellular control systems unsing hybrid computing system. J. theor. Biol. (in press).

- \& Fukuda, N., 1963. Functional analysis. 3. Analysis using a digital circuit combined with an analogue computer. J. theor. Biol. 5, 412-425.

Volmer, M., 1938. Kinetik der Phasenbildung. Springer, Berlin, 220 pp.

Wiener, N. \& Schadé, J. P. (Eds), 1964. Progress in biocybernetics. Elsevier, Amsterdam, 1, $1-204$.

- 1965. Progress in biocybernetics. Elsevier, Amsterdam, 2, 1-273.

YČas, M., Sugita, M. \& Bensam, A., 1965. A model of cell size regulation. J. theor. Biol. 9, $444-470$.

\section{Discussion following the paper by SUGITA}

HEss: Die von Herrn SUGITA theoretisch geforderten Schaltmechanismen der epigenetischen Ebene können ihre stoffliche Grundlage in den von M. EIGEN am Max-Plandk-Institut für physikalische Chemie in Göttingen studierten Übergängen zwischen verschiedenen molekularen Zuständen von Makromolekülen, insbesondere von Polynukleotiden (N größer als 100) (Helixcoil conformations changes) haben. Der Mechanismus der Bildung von WasserstoffbrückenBindungen und hydrophoben Wechselwirkungen ist bei solchen UUbergängen kooperativ, das heißt die Wahrscheinlichkeit des Zustandekommens der Bindungen steigt mit der Zunahme der bereits zustande gekommenen Bindungen. Der Mechanismus hat damit die Eigenschaften eines Phasenüberganges und kann in Mikrosekunden ablaufen. Diese Systeme haben daher die Fähigkeit zu Jam oder Nein-Reaktionen.

Sugrta: Die geschilderte mathematische Analyse ist nur phänomenologisch und muß noch durch molekulare Überlegungen ergänzt werden. Eine Zustandsänderung als Phasenübergang interessiert mich sehr. Bis jetzt hatte ich die Vorstellung, daß der Zustand des Eiweißmoleküls in der Umgebung der DNS für die Ja-Nein-Reaktion Bedeutung hat. Nach Dr. SibaTANI (Biochemiker der Universität Hiroshima), spielt der allosterische Effekt des Repressors in der Schaltreaktion eine Rolle. Eine phasenübergangsähnliche Zustandsänderung der Makromoleküle muß für die mRNS-Synthese begünstigend wirken. 